\title{
Nonswelling Thiol-Yne Cross-Linked Hydrogel Materials as Cytocompatible Soft Tissue Scaffolds
}

\author{
Laura J. Macdougall, ${ }^{\ddagger}$ Maria M. Pérez-Madrigal, ${ }^{\ddagger}$ Maria C. Arno, and Andrew P. Dove*0 \\ Department of Chemistry, University of Warwick, Gibbet Hill Road, Coventry, CV4 7AL, United Kingdom \\ Supporting Information
}

ABSTRACT: A key drawback of hydrogel materials for tissue engineering applications is their characteristic swelling response, which leads to a diminished mechanical performance. However, if a solution can be found to overcome such limitations, there is a wider application for these materials. Herein, we describe a simple and effective way to control the swelling and degradation rate of nucleophilic thiol-yne poly(ethylene glycol) (PEG) hydrogel networks using two straightforward routes: (1) using multiarm alkyne and thiol terminated PEG precursors or (2) introducing a thermoresponsive unit into the PEG network while maintaining their robust mechanical properties. In situ hydrogel materials were formed in under 10 min in PBS solution at $\mathrm{pH} 7.4$ without the need for an external catalyst by using easily accessible precursors. Both pathways resulted in strong tunable hydrogel materials (compressive strength values up to

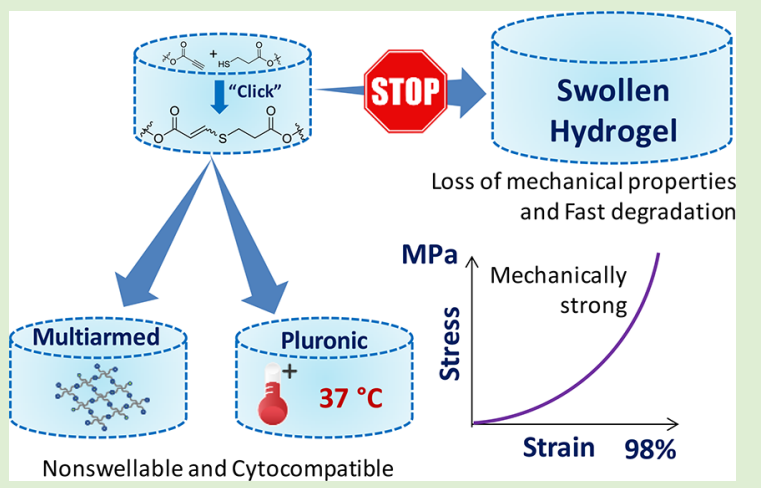

$2.4 \mathrm{MPa}$ ) which could effectively encapsulate cells, thus highlighting their potential as soft tissue scaffolds.

\section{INTRODUCTION}

Hydrogels have become a powerful platform as tissue engineering scaffolds as a consequence of their unique features (high water content, suitable porosity, synthetic versatility, and biocompatibility); however, they suffer from swelling-induced behavior which can limit their applications in this field. ${ }^{1-3}$ Furthermore, these materials must mimic unique biological environments by displaying specific mechanical strength, robustness, and stability. Therefore, the design of hydrogels with finely tuned properties for a specific bioapplication is still a challenging task. ${ }^{4-6}$

To address this issue, biorthogonal click-hydrogels that form rapidly under physiological conditions by covalently bonding nontoxic polymeric chains through easily accessible functional groups, have been synthesized. ${ }^{7-9}$ These materials, which are envisaged as promising soft tissue scaffolds, can be prepared using a wide range of click reactions, for example, thiol-ene, oxime, inverse electron demand Diels-Alder, and strain promoted azide-alkyne cycloaddition (SPAAC), and coppermediated azide- alkyne cycloaddition (CuAAC) ${ }^{7,8}$ Although these chemistries form efficient networks that are biocompatible, some of the functional groups can be difficult to synthesize onto polymer backbones (e.g. strained alkynes). Furthermore, some click reactions follow a UV-initiated radical pathway, using a photoinitiator to conduct the cross-linking reaction releasing free radicals during the cross-linking process. It has been demonstrated that the release of free radicals during the network formation can be cytotoxic to some cell lines, for example, human mesenchymal stem cells (hMSCs) and can cause more toxicity issues than the presence of the photo- initiator. $^{10-12}$ Therefore, by using a radical pathway the cyctotoxcity of the cross-linking reaction can limit the number of different cell lines which can be encapsulated into the network. In contrast, the nucleophilic thiol-yne addition reaction $^{13}$ is highly suitable for hydrogel synthesis as a consequence of its efficient and rapid nature, through the use of easily accessible functional end groups (activated alkyne and thiol functionalities). This allows for the design of unique hydrogels with predefined and robust features. ${ }^{14-17}$

In our previous work, ${ }^{16}$ we reported the synthesis of robust poly(ethylene glycol) (PEG) thiol-yne click-hydrogels with tunable properties. This work utilizes the nucleophilic pathway to form hydrogels using thiol-yne chemistry under slightly basic conditions, $\mathrm{pH}$ 7.4. To exploit the nucleophilic pathway, PEG precursors are easily functionalized with either an activated alkyne (carbonyl adjacent to the alkyne) or thiol end groups allowing the reaction to take place under physiological conditions $\left(37{ }^{\circ} \mathrm{C}\right.$ in $\mathrm{PBS}$ solution, $\mathrm{pH}$ 7.4) without the need of an external catalyst. Through the optimization of the molecular weight, architecture, and composition of the alkyne- and thiol-terminated PEG precursors, these hydrogels displayed a wide range of tunable compressive strengths (up to $2.4 \mathrm{MPa}$ ) and stiffness.

Special Issue: Stimuli-Sensitive and -Responsive Polymer Biomaterials

Received: August 21, 2017

Revised: October 17, 2017

Published: November 10, 2017 
For a hydrogel material to meet the needs of a specific biological environment, the networks need to be designed accordingly. Usually, their mechanical properties are compared to soft tissue (i.e., soft tissue stiffness in the range between $0.25-2.2 \mathrm{kPa}) .{ }^{18}$ In addition to this, and most importantly, the hydrogel's network should be characteristic of an environment that resembles the in vivo setting (i.e., aqueous conditions). However, although some hydrogel systems remain unaltered when immersed in aqueous solutions, ${ }^{19,20}$ in general most swell in aqueous environments at $37^{\circ} \mathrm{C}$, which not only expands and deforms the polymeric network isotropically but also has a major impact on their performance. Swelling-induced effects include loss of mechanical performance, ${ }^{21}$ changes in hydrogel stiffness, ${ }^{22}$ enhanced hydrolytic degradation, ${ }^{1}$ or compromised patient health by excessive compression to the surrounding tissue when used in vivo, thus greatly limiting their biomedical application. Consequently, research into the mechanical response of hydrogels in the swollen state over time is an interesting study for these materials. ${ }^{23}$

Attempts to overcome this drawback rely on synthesizing nonswellable hydrogels, which are able to retain their high compressive modulus and strength despite being immersed in aqueous media. ${ }^{17,24-26}$ Specifically, the swelling induced by the hydrophilic segments of the hydrogel backbone is counterbalanced by either exploiting the thermoresponsive properties of polymers that collapse above a certain temperature, ideally body temperature, ${ }^{17,26,27}$ or by modulating the architecture of the polymeric precursors (i.e., multiarm precursors result in dense hydrogel networks with high cross-linking density and reduced hydrophilicity). ${ }^{25}$

Recently, the former approach was exemplified by Truong et al. ${ }^{17}$ who applied the commercially available triblock PEGPPG-PEG (Pluronic) in the preparation of nucleophilic thiolyne click hydrogels with reduced water uptake at a physiologically relevant temperature. The viscoelastic properties of the resulting hydrogels were characterized by rheology. Notably, however, the authors found that these systems were not suitable for $3 \mathrm{D}$ cell encapsulation and instead led to high levels of cell death, and the effect of swelling-suppression on the compressive strength of thiol-yne click-hydrogels was not assessed.

Herein, we aim to further improve the performance of thiolyne PEG hydrogels, ${ }^{16}$ by rendering them nonswellable and thus controlling their degradation profiles and mechanical performance in aqueous environments. To that end, the thiolfunctionalized PEG precursor was altered to effectively supress swelling by utilizing two different approaches. One route increased the hydrophobic nature of the PEG hydrogels by increasing the number of cross-linking sites in the network using alkyne and thiol-functionalized PEG precursors displaying a 3- or 4-arm architecture (previously 2-arm thiol or alkynefunctionalized PEG were used). ${ }^{16,17}$ This has been previously shown by Kamata and co-workers ${ }^{24}$ as a versatile way of controlling the swelling properties of PEG hydrogels. For the thiol-yne reaction, the reactive end groups are very small, and therefore there is little difference between the unfunctionalized and functionalized precursors, which allows for a straightforward control of the hydrophobicity of the hydrogels through the PEG architecture.

Second, we modified a 2 -arm thermoresponsive segment (Pluronic L-64) as the thiol-moiety within the click-hydrogel network, which allowed us to finely tune their swelling properties by varying the hydrophilic/hydrophobic ratio of the hydrogel polymeric chains. During the characterization of the resulting click hydrogel, comparisons have been drawn between the two routes applied, especially when monitoring the evolution of their compressive strength with time after being immersed in PBS solution at $37^{\circ} \mathrm{C}$. Most importantly, their potential as soft tissue scaffolds has been assessed through encapsulated cell studies over a $72 \mathrm{~h}$ period.

\section{EXPERIMENTAL SECTION}

Materials. 4-arm PEG-tetrahydroxyl (molar mass $2.0 \mathrm{~kg} \mathrm{~mol}^{-1}$ ) was purchased from JenKem Technology, U.S.A. All other reagents were purchased from Sigma-Aldrich or Fisher Scientific and used without purification.

Instrumental Methods. ${ }^{1} \mathrm{H}$ NMR spectra were recorded on a Bruker DPX-400 spectrometer at $293 \mathrm{~K}$. Chemical shifts are reported as $\delta$ in parts per million (ppm) and referenced to the chemical shift of the residual solvent resonances $\left(\mathrm{CDCl}_{3},{ }^{1} \mathrm{H} \delta=7.26 \mathrm{ppm} ;\left(\mathrm{CD}_{3}\right)_{2} \mathrm{CO}\right.$, $\left.{ }^{1} \mathrm{H} \delta=2.05 \mathrm{ppm}\right)$.

Size exclusion chromatography (SEC) was used to determine the molar masses and molar mass distributions (dispersities, $\bigoplus_{\mathrm{M}}$ ) of the synthesized polymers. SEC conducted in chloroform $\left(\mathrm{CHCl}_{3}\right)(0.5 \%$ $\mathrm{NEt}_{3}$ ) used a Varian PL-SEC 50 system equipped with $2 \times$ PLgel $5 \mu \mathrm{M}$ MIXED-D columns in series and a differential refractive index (RI) detector at a flow rate $1.0 \mathrm{~mL} \mathrm{~min}{ }^{-1}$. The system was calibrated against a Varian Polymer Laboratories Easi-Vial poly(styrene) (PS) standard and analyzed by the software package Cirrus v3.3.

SEC conducted in N,N-dimethylformamide (DMF) (5 mM $\mathrm{NH}_{4} \mathrm{BF}_{4}$ ) used a Varian PL-SEC 50 system equipped with $2 \times$ PLgel $5 \mu \mathrm{M}$ MIXED-C+ guard columns in series and a differential RI

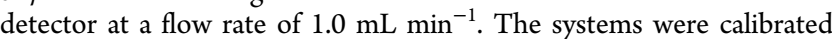
against Varian Polymer Laboratories Easi-Vial linear poly(methyl methacrylate) (PMMA) standards and analyzed by the software package Cirrus v3.3.

Lower critical solution temperature (LCST) and cloud point measurements for Pluronic L-64 before and after modification were recorded using a PerkinElmer UV-vis Spectrometer (Lambda 35) equipped with a Peltier temperature control system, using a wavelength of $500 \mathrm{~nm}$ and a heating/cooling rate of $1{ }^{\circ} \mathrm{C} \mathrm{min}^{-1}$. The polymer was dissolved in water at $1 \%$ wt concentration and submitted to three heating-cooling cycles. Transmittance curves were normalized for clarity, and the cloud point of each sample measured at $50 \%$ of normalized transmittance.

Rheological testing was carried out using an Anton Parr MCR 302 rheometer equipped with parallel plate configuration with a diameter of $50 \mathrm{~mm}$. A Peltier system was used to maintain the temperature at 20 ${ }^{\circ} \mathrm{C}$ throughout the study. Data was analyzed using RheoCompass software.

Compression testing was carried out using single column universal materials testing machine M100-1CT Testometric with a load cell of 1 $\mathrm{kN}$. Data was analyzed using Wintest analysis software.

Cryogenic scanning electron microscopy (cryo-SEM) was performed on ZEISS SUPRA 55-VP equipped with cold stage and sample preparation chamber.

Evaluation of cell viability during 3D cell encapsulation experiments was carried out using a Zeiss LSM 880 confocal fluorescence microscope. Staining for live cells (Calcein, Ex. $=495 \mathrm{~nm}, \mathrm{Em}$. = $515 \mathrm{~nm}$ ) was excited with a $488 \mathrm{~nm}$ laser, while staining for dead cells (Ethidium homodimer, $\mathrm{Ex}=528 \mathrm{~nm}, \mathrm{Em}=617 \mathrm{~nm}$ ) was excited with a $514 \mathrm{~nm}$ laser. Z-stacks with an average thickness of $400 \mu \mathrm{m}$ were collected from different zones of the samples and maximum intensity projections were obtained from each Z-stack. Images were processed using Zen (blue edition) and Image software.

Synthesis of Alkyne and Thiol Precursors. Synthesis of 4-Arm Alkyne Functionalized PEG. To a suspension of 4-arm $\mathrm{PEG}_{2 \mathrm{k}}-\mathrm{OH}$ (molar mass $2.0 \mathrm{~kg} \mathrm{~mol}^{-1}, 10 \mathrm{~g}, 5 \mathrm{mmol}$ ) in benzene $(75 \mathrm{~mL}$ ) and toluene $(75 \mathrm{~mL})$ was added 2 drops of concentrated $\mathrm{H}_{2} \mathrm{SO}_{4}$. The solution was heated to $80{ }^{\circ} \mathrm{C}$ with stirring to obtain a clear homogeneous solution. To this solution, propiolic acid (2.8 g, 40 $\mathrm{mmol}$ ) was added and the solution was heated to reflux under Dean- 
Stark conditions. After no more water was collected in the condenser (about $20 \mathrm{~h}$ ), the solution was allowed to cool to room temperature and the solvents were removed in vacuo. The resultant oil was dissolved in $\mathrm{CH}_{2} \mathrm{Cl}_{2}(100 \mathrm{~mL})$ and washed with saturated $\mathrm{NaHCO}_{3}$ solution $(20 \mathrm{~mL})$ and brine $(20 \mathrm{~mL})$. The organic phase was dried $\left(\mathrm{MgSO}_{4}\right)$ and stirred with charcoal (about $0.1 \mathrm{~g}$ ) for $30 \mathrm{~min}$ at $40^{\circ} \mathrm{C}$. The solution was filtered through Celite 545 and the solvent was evaporated to collect product as a clear to light yellow oil (yield $6.1 \mathrm{~g}$, $61 \%) .{ }^{1} \mathrm{H} \mathrm{NMR}\left(\left(\mathrm{CD}_{3}\right)_{2} \mathrm{CO}, 400 \mathrm{MHz}\right): \delta 4.32-4.35\left(\mathrm{t},{ }^{3} \mathrm{~J}_{\mathrm{HH}}=8 \mathrm{~Hz}\right.$, $\left.-\mathrm{CH}_{2} \mathrm{OCO}-\right), 3.90(\mathrm{~s},-\mathrm{CH} \equiv \mathrm{CC}(\mathrm{O}) \mathrm{O}-), 3.72-3.74(\mathrm{~m}$, $-\mathrm{OCH}_{2} \mathrm{CH}_{2} \mathrm{O}-$ ), $3.6\left(\mathrm{~s}, \mathrm{CCH}_{2} \mathrm{O}\right) .{ }^{1} \mathrm{H}$ NMR spectroscopy indicated about $93 \%$ conversion of the hydroxyl group to propiolate group. SEC (DMF): $M_{\mathrm{n}}=5.9 \mathrm{~kg} \mathrm{~mol}^{-1}\left(\bigoplus_{\mathrm{M}}=1.08\right)$.

Synthesis of 3-Arm Alkyne Functionalized PEG. In a typical esterification, as stated in the above procedure, glycerol ethoxylate (molar mass $1.0 \mathrm{~kg} \mathrm{~mol}^{-1}, 10 \mathrm{~g}, 10 \mathrm{mmol}$ ) was esterified with propiolic acid $(4.2 \mathrm{~g}, 60 \mathrm{mmol})$ to collect the product as a light yellow oil (yield $8.1 \mathrm{~g}, 70 \%) .{ }^{1} \mathrm{H}$ NMR $\left(\left(\mathrm{CD}_{3}\right)_{2} \mathrm{CO}, 400 \mathrm{MHz}\right): \delta 4.32-4.34\left(\mathrm{t},{ }^{3} \mathrm{~J}_{\mathrm{HH}}=\right.$ $\left.8 \mathrm{~Hz},-\mathrm{CH}_{2} \mathrm{OCO}-\right), 3.89(\mathrm{~s},-\mathrm{CH} \equiv \mathrm{CC}(\mathrm{O}) \mathrm{O}-), 3.71-3.74(\mathrm{~m}$, $\left.-\mathrm{OCH}_{2} \mathrm{CH}_{2} \mathrm{O}-\right), 3.58$ (s, $\left.-\mathrm{CCH}_{2} \mathrm{O}\right) .{ }^{1} \mathrm{H}$ NMR spectroscopy indicated about $92 \%$ conversion of the hydroxyl group to propiolate group. SEC (DMF): $M_{\mathrm{n}}=3.3 \mathrm{~kg} \mathrm{~mol}^{-1}\left(\bigoplus_{\mathrm{M}}=1.04\right)$.

Synthesis of 2-Arm Thiol Functionalized PEG (1, 2, or $3 \mathrm{~kg}$ $\left.\mathrm{mol}^{-1}\right)$. In a typical esterification, as stated in the above procedure, 2arm PEG-OH (10 g, $10 \mathrm{mmol}$ ) was esterified with 3-mercaptopropionic acid ( 2 equiv per arm $/ 0.5 \mathrm{~kg} \mathrm{~mol}^{-1}$ ) to collect the product as a white solid.

$\mathrm{PEG}_{1 k}(\mathrm{SH})_{2}$ (Yield $\left.9.4 \mathrm{~g}, 80 \%\right) .{ }^{1} \mathrm{H}$ NMR $\left(\mathrm{CDCl}_{3}, 400 \mathrm{MHz}\right): \delta$ $4.25-4.27\left(\mathrm{t},{ }^{3} J_{\mathrm{HH}}=8,-\mathrm{CH}_{2} \mathrm{OCO}-\right), 3.65\left(\mathrm{~m},-\mathrm{OCH}_{2} \mathrm{CH}_{2} \mathrm{O}-\right)$, $2.75-2.78\left(\mathrm{q},{ }^{3} J_{\mathrm{HH}}=12,-\mathrm{OCCH}_{2} \mathrm{CH}_{2} \mathrm{SH}\right), 2.66-2.69\left(\mathrm{t},{ }^{3} J_{\mathrm{HH}}=12\right.$, $\left.-\mathrm{OCCH}_{2} \mathrm{CH}_{2} \mathrm{SH}\right), \quad 1.66-1.68\left(\mathrm{t},{ }^{3} \mathrm{~J}_{\mathrm{HH}}=8,-\mathrm{SH}\right),{ }^{1} \mathrm{H} \mathrm{NMR}$ spectroscopy indicated about $96 \%$ conversion of the hydroxyl group to mercaptopropionate group. SEC $\left(\mathrm{CHCl}_{3}\right): M_{\mathrm{n}}=1.1 \mathrm{~kg} \mathrm{~mol}^{-1}\left(\bigoplus_{\mathrm{M}}\right.$ $=1.24)$.

$\mathrm{PEG}_{2 \mathrm{k}}(\mathrm{SH})_{2}$ (Yield $9.2 \mathrm{~g}$, 85\%). ${ }^{1} \mathrm{H}$ NMR $\left(\mathrm{CDCl}_{3}, 400 \mathrm{MHz}\right): \delta$ $4.26-4.28\left(\mathrm{t},{ }^{3} \mathrm{~J}_{\mathrm{HH}}=8,-\mathrm{CH}_{2} \mathrm{OCO}-\right), 3.65\left(\mathrm{~m},-\mathrm{OCH}_{2} \mathrm{CH}_{2} \mathrm{O}-\right)$, $2.75-2.80\left(\mathrm{q},{ }^{3} J_{\mathrm{HH}}=12,-\mathrm{OCCH}_{2} \mathrm{CH}_{2} \mathrm{SH}\right), 2.67-2.70\left(\mathrm{t},{ }^{3} \mathrm{~J}_{\mathrm{HH}}=12\right.$, $\left.-\mathrm{OCCH}_{2} \mathrm{CH}_{2} \mathrm{SH}\right), \quad 1.67-1.69\left(\mathrm{t},{ }^{3} \mathrm{~J}_{\mathrm{HH}}=8,-\mathrm{SH}\right),{ }^{1} \mathrm{H}$ NMR spectroscopy indicated about > 99\% conversion of the hydroxyl group to mercaptopropionate group. SEC $\left(\mathrm{CHCl}_{3}\right): M_{\mathrm{n}}=2.7 \mathrm{~kg}$ $\mathrm{mol}^{-1}\left(\oplus_{M}=1.26\right)$.

$\mathrm{PEG}_{3 \mathrm{k}}(\mathrm{SH})_{2}$ (Yield $\left.9.3 \mathrm{~g}, 88 \%\right) .{ }^{1} \mathrm{H}$ NMR $\left(\mathrm{CDCl}_{3}, 400 \mathrm{MHz}\right): \delta$ $4.26-4.28\left(\mathrm{t},{ }^{3} \mathrm{~J}_{\mathrm{HH}}=8,-\mathrm{CH}_{2} \mathrm{OCO}-\right), 3.65\left(\mathrm{~m},-\mathrm{OCH}_{2} \mathrm{CH}_{2} \mathrm{O}-\right)$, $2.71-2.78\left(\mathrm{q},{ }^{3} \mathrm{~J}_{\mathrm{HH}}=12,-\mathrm{OCCH}_{2} \mathrm{CH}_{2} \mathrm{SH}\right), 2.63-2.67\left(\mathrm{t},{ }^{3} \mathrm{~J}_{\mathrm{HH}}=12\right.$, $\left.-\mathrm{OCCH}_{2} \mathrm{CH}_{2} \mathrm{SH}\right), 1.62-1.68\left(\mathrm{t},{ }^{3} \mathrm{~J}_{\mathrm{HH}}=8,-\mathrm{SH}\right),{ }^{1} \mathrm{H} \mathrm{NMR}$ spectroscopy indicated about $84 \%$ conversion of the hydroxyl group to mercaptopropionate group. SEC (DMF): $M_{\mathrm{n}}=8.7 \mathrm{~kg} \mathrm{~mol}^{-1}\left(\bigoplus_{\mathrm{M}}=\right.$ $1.1)$.

Synthesis of 2-Arm Thiol-Functionalized Pluronic L-64 (PEG$\left.P P G-P E G 2.9 \mathrm{~kg} \mathrm{~mol}^{-1}\right)$. In a typical esterification, as stated in the above procedure, PEG-PPG-PEG (10 g, $3.5 \mathrm{mmol})$ was esterified with 3-mercaptopropionic acid $(1.46 \mathrm{~g}, 13.8 \mathrm{mmol})$ to collect the product as a white solid (yield $8.8 \mathrm{~g}, 78 \%) .{ }^{1} \mathrm{H}$ NMR $\left(\mathrm{CDCl}_{3}, 400\right.$ $\mathrm{MHz}): \delta 4.20-4.23\left(\mathrm{t},{ }^{3} \mathrm{~J}_{\mathrm{HH}}=8,-\mathrm{CH}_{2} \mathrm{OCO}-\right), 3.65(\mathrm{~m}$, $\left.-\mathrm{OCH}_{2} \mathrm{CH}_{2} \mathrm{O}-\right), 3.49\left(\mathrm{~m},-\mathrm{OCH}_{2} \mathrm{CH}\left(\mathrm{CH}_{3}\right) \mathrm{O}-\right), 2.69-2.76$ (q, $\left.{ }^{3} J_{\mathrm{HH}}=12,-\mathrm{OCCH}_{2} \mathrm{CH}_{2} \mathrm{SH}\right), 2.61-2.65\left(\mathrm{t},{ }^{3} J_{\mathrm{HH}}=12\right.$, $\left.-\mathrm{OCCH}_{2} \mathrm{CH}_{2} \mathrm{SH}\right), 1.61-1.66\left(\mathrm{t},{ }^{3} \mathrm{~J}_{\mathrm{HH}}=8,-\mathrm{SH}\right), 1.08-1.09\left(\mathrm{~d},{ }^{3} J_{\mathrm{HH}}\right.$ $\left.=4,-\mathrm{OCH}_{2} \mathrm{CH}\left(\mathrm{CH}_{3}\right) \mathrm{O}-\right),{ }^{1} \mathrm{H}$ NMR spectroscopy indicated about 93\% conversion of the hydroxyl group to mercaptopropionate group. SEC (DMF): $M_{\mathrm{n}}=5.8 \mathrm{~kg} \mathrm{~mol}^{-1}\left(\bigoplus_{\mathrm{M}}=1.2\right)$.

Synthesis of 3-Arm Thiol Functionalized PEG $\left(1 \mathrm{~kg} \mathrm{~mol}^{-1}\right)$. In a typical esterification as stated in the above procedure, glycerol ethoxylate (molar mass $1.0 \mathrm{~kg} \mathrm{~mol}^{-1}, 10 \mathrm{~g}, 10 \mathrm{mmol}$ ) was esterified using 3-mercaptopropionic acid (4.2 g, $60 \mathrm{mmol}$ ) (yield 9.4 g, 74\%). ${ }^{1} \mathrm{H}$ NMR $\left(\mathrm{CDCl}_{3}, 400 \mathrm{MHz}\right): \delta 4.20-4.22\left(\mathrm{t},{ }^{3} J_{\mathrm{HH}}=8\right.$, $\left.-\mathrm{CH}_{2} \mathrm{OCO}-\right), 3.58\left(\mathrm{~m},-\mathrm{OCH}_{2} \mathrm{CH}_{2} \mathrm{O}-\right), 2.69-2.74\left(\mathrm{q},{ }^{3} J_{\mathrm{HH}}=12\right.$, $\left.-\mathrm{OCCH}_{2} \mathrm{CH}_{2} \mathrm{SH}\right), 2.61-2.64\left(\mathrm{t},{ }^{3} \mathrm{~J}_{\mathrm{HH}}=12,-\mathrm{OCCH}_{2} \mathrm{CH}_{2} \mathrm{SH}\right), 1.61-$ $1.66\left(\mathrm{t},{ }^{3} \mathrm{~J}_{\mathrm{HH}}=20,-\mathrm{SH}\right),{ }^{1} \mathrm{H}$ NMR spectroscopy indicated about $>99 \%$ conversion of the hydroxyl group to mercaptopropionate group. SEC (DMF): $M_{\mathrm{n}}=10.6 \mathrm{~kg} \mathrm{~mol}^{-1}\left(\bigoplus_{\mathrm{M}}=1.08\right)$.
Synthesis of 4-Arm Thiol Functionalized PEG $\left(2 \mathrm{~kg} \mathrm{~mol}^{-1}\right)$. In a typical esterification, as stated in the above procedure, 4-arm $\mathrm{PEG}_{2 \mathrm{k}}-$ $\mathrm{OH}$ (molar mass $=2.0 \mathrm{~kg} \mathrm{~mol}^{-1}, 10 \mathrm{~g}, 5 \mathrm{mmol}$ ) was esterified using 3mercaptopropionic acid $(4.2 \mathrm{~g}, 40 \mathrm{mmol}$ ) (yield $9.1 \mathrm{~g}, 77 \%) .{ }^{1} \mathrm{H}$ NMR $\left(\mathrm{CDCl}_{3}, 400 \mathrm{MHz}\right): \delta 4.21-4.24\left(\mathrm{t},{ }^{3} \mathrm{~J}_{\mathrm{HH}}=12,-\mathrm{CH}_{2} \mathrm{OCO}-\right), 3.58$ $\left(\mathrm{m},-\mathrm{OCH}_{2} \mathrm{CH}_{2} \mathrm{O}-\right)$, 2.71-2.76 (q, $\left.{ }^{3} J_{\mathrm{HH}}=20,-\mathrm{OCCH}_{2} \mathrm{CH}_{2} \mathrm{SH}\right)$, $2.63-2.66\left(\mathrm{t},{ }^{3} J_{\mathrm{HH}}=12,-\mathrm{OCCH}_{2} \mathrm{CH}_{2} \mathrm{SH}\right), 1.63-1.67\left(\mathrm{t},{ }^{3} J_{\mathrm{HH}}=16\right.$, $-\mathrm{SH}),{ }^{1} \mathrm{H}$ NMR spectroscopy indicated about $>99 \%$ conversion of the hydroxyl group to mercaptopropionate group. SEC (DMF): $M_{\mathrm{n}}=$ $4.7 \mathrm{~kg} \mathrm{~mol}^{-1}\left(\bigoplus_{\mathrm{M}}=1.06\right)$.

Hydrogel Fabrication. A 1:1 molar ratio of alkyne group to thiol group was used for all gelations by thiol-yne chemistry, and the precursor content was kept at $10 \mathrm{wt} \%$. In a typical procedure for making a thiol-yne PEG gel, $\mathrm{PEG}_{1 \mathrm{k}}-(\mathrm{SH})_{2}\left(22.9 \mathrm{mg}, 1.95 \times 10^{-3}\right.$ $\mathrm{mmol}$ ) was dissolved in $200 \mu \mathrm{L}$ of PBS pH 7.4 solution. A separate solution of $\mathrm{PEG}_{2 \mathrm{k}^{\mathrm{k}}}(\mathrm{C} \equiv \mathrm{CH})_{4}\left(21.5 \mathrm{mg}, 9.74 \times 10^{-3} \mathrm{mmol}\right)$ in $200 \mu \mathrm{L}$ of PBS pH 7.4 solution. The two solutions were mixed together on a vortex mixer for $5 \mathrm{~s}$. The mixture was then injected into a mold suitable for the chosen analysis. All the preparation steps for thermoresponsive hydrogels were performed below $10{ }^{\circ} \mathrm{C}$ by cooling the solutions in an ice bath. For the blended hydrogels, a 1:1 molar ratio of alkyne group to thiol group was maintained. Different molar ratio of each thiol was used to tune the properties of the resulting hydrogels. The precursors were diluted with PBS solution and the thiol precursors were mixed together before being added to the diluted alkyne precursor.

Hydrogel Characterization. Gel Fraction (GF) and Equilibrium Water Content (EWC). Hydrogels were fabricated as stated in the above procedure. To determine the gel fraction (GF) the hydrogels were lyophilized and their weights $\left(W_{\mathrm{g}}\right)$ recorded. The hydrogels were then allowed to swell in deionized water for 3 days with frequent changes in water to extract unreacted polymers. The hydrogels were then lyophilized and their weights $\left(W_{\mathrm{r}}\right)$ were recorded again. All measurements were repeated in triplicate. The gel fraction was expressed as

$$
\text { Gel Fraction }(\%)=\frac{W_{\mathrm{r}}}{W_{\mathrm{g}}} \times 100
$$

To determine the equilibrium water content (EWC) the prepared hydrogels were allowed to swell in PBS solution for 1 day so that swelling could reach equilibrium. The surface water was then removed with soft tissue paper and the weights recorded $\left(W_{s}\right)$. The hydrogels were then lyophilized and the weights recorded $\left(W_{\mathrm{d}}\right)$. All measurements were repeated in triplicate. The equilibrium water content was expressed as

$$
\operatorname{EWC}(\%)=\frac{W_{\mathrm{s}}-W_{\mathrm{d}}}{W_{\mathrm{d}}} \times 100
$$

Mesh Size Calculations. Flory-Rehner calculations were used to determine each thiol-yne PEG hydrogel mesh size. ${ }^{28,29}$ All measurements were repeated in triplicate.

$$
\S=v_{2}^{-1 / 3}\left(\bar{r}_{0}^{2}\right)^{1 / 2}
$$

Rheological Testing. All rheology was performed on an Anton Parr MCR 302 rheometer fitted with a parallel plate configuration (diameter of $50 \mathrm{~mm}$ ) at $20{ }^{\circ} \mathrm{C}$. In a typical rheological test for gelation kinetics, $\mathrm{PEG}_{1 \mathrm{k}}(\mathrm{SH})_{2}\left(56.8 \mathrm{mg}, 4.83 \times 10^{-2} \mathrm{mmol}\right)$ and $\mathrm{PEG}_{2 \mathrm{k}}(\mathrm{C} \equiv \mathrm{CH})_{4}\left(53.3 \mathrm{mg}, 2.41 \times 10^{-2} \mathrm{mmol}\right)$ were dissolved in separate solutions of $500 \mu \mathrm{L}$ PBS pH 7.4. The two solutions were drawn up in a $1 \mathrm{~mL}$ syringe and injected on to the lower plate, at 20 ${ }^{\circ} \mathrm{C}$. The upper plate was immediately lowered to a plate separation of $0.5 \mathrm{~mm}$ and the measurement was started. A frequency of $5 \mathrm{~Hz}$ and a strain of $5 \%$ was applied to minimize interference with the gelation process and to keep the measurement within the linear viscoelastic region. The normal force was also kept constant at $0 \mathrm{~N}$. The gelation kinetics was characterized by the evolution of storage moduli $\left(G^{\prime}\right)$ and loss moduli $\left(G^{\prime \prime}\right)$ as a function of time. The gel point was determined by the crossover between the $G^{\prime}$ and $G^{\prime \prime}$. A point was recorded each second until the $G^{\prime}$ and $G^{\prime \prime}$ plateaued. The amplitude sweeps were 
carried out on the gel formed from this experiment. The amplitude sweep applied a constant frequency of $10 \mathrm{rad} / \mathrm{s}$ and the strain was ramped logarithmically from $0.01 \%$ to $100 \%$. The normal force was kept constant at $0 \mathrm{~N}$ and 6 points were recorded for each decade. All measurements were repeated in triplicate and representative charts are shown

Uniaxial Compressive Tests. All uniaxial compressive testing was performed on a M100-1CT Testometric fitted with a load cell of $1 \mathrm{kN}$. Hydrogel samples were prepared with a $2 \mathrm{~mL}$ syringe to give a cylindrical shape with a diameter of $9 \mathrm{~mm}$ and length of $4 \mathrm{~mm}$. Samples were left to cure for $1 \mathrm{~h}$ after forming, to ensure the crosslinking reaction was complete before being tested. A preload force of $0.1 \mathrm{~N}$ was set and each test was carried out at a compression velocity of $5 \mathrm{~mm} \mathrm{~min}{ }^{-1}$. Each gel was subject to $98 \%$ strain in order to determine the ultimate compressive stress and strain. All compression tests were repeated 10 times and an average of the data was taken to find the ultimate compressive stress and strain. Data was analyzed using Wintest analysis software. Young's modulus was calculated from the initial $10 \%$ of the stress/strain curve and is defined as

$$
\text { Young's modulus }=\frac{\text { Difference in Stress }}{\text { Difference in Strain }}
$$

Cryogenic Scanning Electron Microscopy. Cryogenic scanning electron microscopy (cryo-SEM) was performed on ZEISS SUPRA $55-\mathrm{VP}$ equipped with cold stage and sample preparation chamber. In a typical procedure, a hydrogel sample was formed in situ on a stub and the top layer was sliced off. The stub was placed in a prefrozen stub adaptor and frozen in liquid nitrogen $\left(-195{ }^{\circ} \mathrm{C}\right)$ which was obtained by placing the sample in liquid nitrogen under vacuum. The stub was then transferred to the cold stage (at $-125{ }^{\circ} \mathrm{C}$ ) of the preparation chamber connecting to the SEM chamber. The frozen sample was surface fractured and sublimated at $-95{ }^{\circ} \mathrm{C}$ for $15 \mathrm{~min}$ to reveal the cross-sectional surface. The temperature was then brought down to $-125{ }^{\circ} \mathrm{C}$ and the sample was sputter coated with platinum before being transferred under vacuum into the SEM chamber, which was kept at $-186{ }^{\circ} \mathrm{C}$ for imaging. The accelerating voltage was set at $2 \mathrm{kV}$ to avoid burning the sample.

Swelling and Degradation Studies. Hydrogels were fabricated as stated in the previous procedure and left to cure for $1 \mathrm{~h}$ at room temperature. The prepared hydrogels were then placed in PBS solution $\mathrm{pH} 7.4$ and incubated at $37^{\circ} \mathrm{C}$ in an orbital shaker-incubator (Model ES-20, Grant Instruments (Cambridge) Ltd.) with a shaking speed of $80 \mathrm{rpm}$. The PBS solution was replaced regularly to remove unreacted PEG precursors and to prevent the buildup of solute concentration. At preset time intervals, the hydrogels were removed, gently blotted dry and the weight was recorded. The swelling factor (SF) and degradation was monitored by the percentage of weight of the hydrogel at each time point $(t)$ compared to the weight before submersion which is defined as

$$
\text { Swelling Factor }(\%)=\frac{W_{\mathrm{t}}}{W_{0}} \times 100
$$

where $W \mathrm{t}$ is the weight measured at specific time point and $W_{0}$ is the initial wet weight before immersed (after $1 \mathrm{~h}$ ).

Biocompatibility Studies and 3D Cell Encapsulation. MC3T3-E1 were purchased from Public Health England and cultured as advised by supplier in MEM- $\alpha$ medium with addition of $10 \%$ FBS and $1 \%$ penicillin/streptomycin. For the biocompatibility studies, hydrogels were prepared in culture medium in 24 wells cell culture inserts with a $0.4 \mu \mathrm{m}$ pore PET membrane, as described in the previous section, in a total volume of $200 \mu \mathrm{L}$. After 30 min incubation at $37^{\circ} \mathrm{C}, 100,000$ cells suspended in $20 \mu \mathrm{L}$ of medium were seeded on top of the hydrogel, and the material was incubated for $2 \mathrm{~h}$ before addition of fresh medium on top and around the hydrogel. Bioviability was assessed using a PrestoBlue viability assay. Fluorescence was measured using a BioTek plate reader $\left(\lambda_{\mathrm{Ex}}=530 \mathrm{~nm}, \lambda_{\mathrm{Em} .}=590 \mathrm{~nm}\right)$. For 3D encapsulation studies, 500,000 cells per hydrogel were suspended with the alkyne precursor, followed by addition of the thiol precursor prior mixing to obtain a $200 \mu \mathrm{L}$ hydrogel. Cells were incubated up to $72 \mathrm{~h}$, after which they were stained with calcein for live cells $\left(\lambda_{\mathrm{Ex} .}=495, \lambda_{\mathrm{Em} .}=515\right)$ and ethidium homodimer for dead cells $\left(\lambda_{\mathrm{Ex}}=528, \lambda_{\mathrm{Em} .}=617\right)$ and imaged using a confocal fluorescence microscope. Finally, cell viability was also evaluated in the presence of degradation products from hydrogels incubated in complete culture medium (MEM- $\alpha$ with $10 \%$ FBS and $1 \%$ pen/strep). Hence, three hydrogels for each system were prepared as previously described and then immersed in culture medium $(5 \mathrm{~mL})$ for 6 days at $37^{\circ} \mathrm{C}$ under slight shaking $(80 \mathrm{rpm})$. The solutions were then sterile filtered $(0.22$ $\mu \mathrm{m})$. MC3T3 cells were seeded at 2000 cells $\mathrm{cm}^{-2}$ in 24 well plates and incubated in culture medium for $24 \mathrm{~h}$. Serial dilutions of each degraded gel were prepared (from 0.625 to $5 \mathrm{mg} \mathrm{mL}^{-1}$ ), and $1 \mathrm{~mL}$ of each dilution was added to each well and incubated under standard culture conditions $\left(37^{\circ} \mathrm{C}, 5 \% \mathrm{CO}_{2}\right)$. Cell viability was evaluated using the PrestoBlue $\left(\lambda_{\mathrm{Ex}}=530 \mathrm{~nm}, \lambda_{\mathrm{Em} .}=590 \mathrm{~nm}\right)$ metabolic assay at three time points, $24 \mathrm{~h}, 72 \mathrm{~h}$, and 7 days. Experiments were performed in triplicate.

\section{RESULTS AND DISCUSSION}

Synthesis of Alkyne- and Thiol-Terminated PEG Precursors. The design of nonswellable hydrogels has been achieved by two accessible strategies that alter the swelling characteristics of our previous robust PEG-based hydrogels prepared through the nucleophilic thiol-yne addition reaction (Scheme 1). ${ }^{16}$ Overall, both routes use simple end group

Scheme 1. Nucleophilic Base-Catalyzed Thiol-Yne Reaction

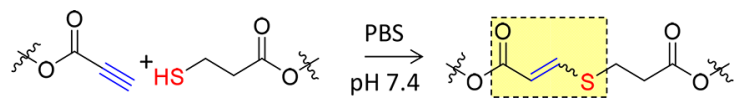

modifications which are highly efficient with conversion values higher than $84 \%$ (Figures S1-S9 and Table S1). The hydrogel nomenclature is dependent on the PEG precursors, each precursor is denoted considering the number of arms, molecular weight, and the incorporated functionality, $\mathbf{S}$ for thiol or A for alkyne. Hence, $3_{1 \text { s }}$ refers to the 3 -arm thiolterminated PEG precursor $\left(1 \mathrm{~kg} \mathrm{~mol}^{-1}\right)$.

To increase the cross-linking density of the hydrogel network (route one), and thus reducing the hydrophilicity of the system, alkyne- and thiol-terminated polymeric precursors were prepared by modifying multiarm PEG-hydroxyl groups (Scheme 2a). Specifically, 3-arm $\left(1 \mathrm{~kg} \mathrm{~mol}^{-1}\right)$ and 4-arm (2 $\mathrm{kg} \mathrm{mol}^{-1}$ ) PEG polymers were functionalized through Fischer esterification of the hydroxyl end-group with either propiolic acid or mercaptopropionic acid. The thermoresponsive nonswellable click hydrogels (route two) were synthesized using a thiol-terminated Pluronic PEG precursor, PEG-PPG-PEG (2900 $\mathrm{g} \mathrm{mol}^{-1}$, Pluronic L-64, 40\% of EG content) with mercaptopropionic acid, hereafter denoted $\mathbf{2 P}_{\mathbf{3 S}}$ (Scheme 2b). ${ }^{17}$ After modification, the lower critical solution temperature (LCST) of the commercially available Pluronic decreased from $55-60{ }^{\circ} \mathrm{C}$ down to $25-35{ }^{\circ} \mathrm{C}$ (SI, Figure S10), which is below $37{ }^{\circ} \mathrm{C}$, and thus highly suitable for our application. Consequently, when injected into the body, the $\mathbf{2 P}_{3}$ s segments will induce the collapse of the click-hydrogel network preventing it from swelling.

Once the modified PEG precursors were synthesized, clickhydrogels with $10 \% \mathrm{w} / \mathrm{v}$ polymer content were subsequently prepared by mixing solutions containing a 1:1 molar ratio of alkyne to thiol end groups in PBS solution at $\mathrm{pH}$ 7.4.

Characterization of Swellable PEG-Containing ClickHydrogels. In general, most hydrogels swell when placed in aqueous solution; consequently, their volume increases, and 
Scheme 2. Nonswellable Click-Hydrogels ${ }^{a}$<smiles>[Y]OCCOCC(COCCO[Y])OCO[Y]</smiles>
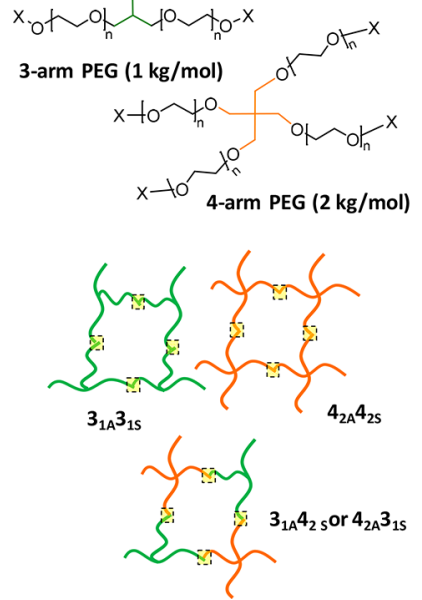

b)
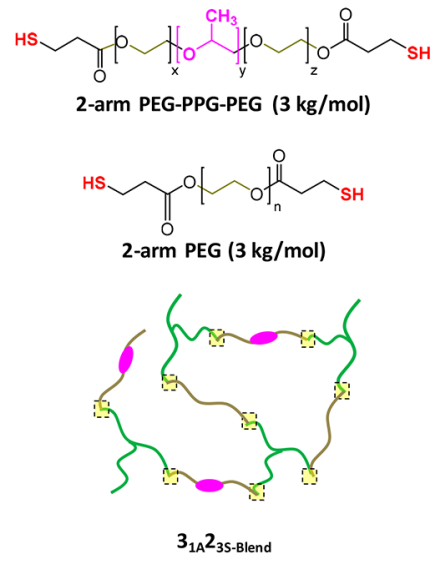

${ }^{a}$ Based on (a) multi-arm and (b) thermoresponsive PEG precursors.

severe alterations of their mechanical properties occur. In order to characterize the swelling behavior of the previously reported related system, thiol-yne PEG-based click-hydrogels $\left(3_{1 \mathrm{~A}} \mathbf{2}_{1 \mathrm{~S}}\right.$, $3_{1 \mathrm{~A}} \mathbf{2}_{2 \mathrm{~S}}$, and $\left.3_{1 \mathrm{~A}} 2_{3 \mathrm{~S}}\right)$ were prepared using 2 -arm thiol-terminated PEG precursors to provide control measurements. As expected, these systems undergo swelling up to $179.9 \% \pm 29.4 \%, 443.0 \%$ $\pm 7.4 \%$, and $408.0 \% \pm 9.0 \%$, respectively, before degrading completely in the aqueous solution within 3 and 4 days (Figure 1a). For thiol-yne click-hydrogels, bulk hydrolytic degradation occurs, which results from the combination of the diffusion of water into a polymer network and the subsequent random cleavage of hydrolyzable bonds. ${ }^{30-32}$ In addition, carboxylic acid groups, from the ester cleavage, display an autocatalytic effect. The polymeric nature of these degradation products, many of which are likely to remain attached to the network,
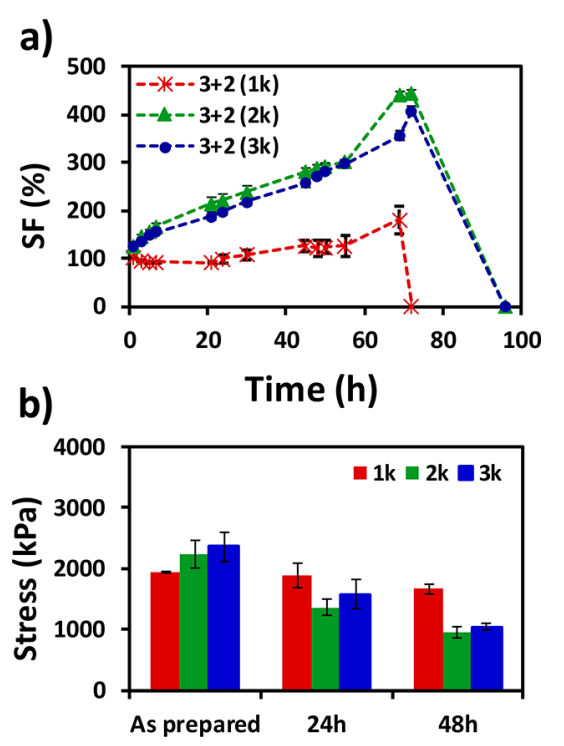

Figure 1. Swellable hydrogels characterization $\left(3_{1 \mathrm{~A}} 2_{1 S}\right.$, red; $3_{1 \mathrm{~A}} 2_{2 S}$, green; $3_{1 \mathrm{~A}} 2_{3 \mathrm{~S}}$, blue). (a) Swelling factor (SF) (\%) as a function of time in PBS solution at $37^{\circ} \mathrm{C}$ and (b) evolution of stress at breaking with swelling time. Compressive modulus data can be found in the SI (Table S3 and Figure S11). accelerate degradation and contribute to the loss of structural and mechanical stability. Ultimately, as we observe, the hydrogel network swells and then dissolves into the PBS solution. $^{33}$

Additionally, swelling experiments also reveal information on the equilibrium water content (EWC) and mesh size of the hydrogel networks. Both features are key factors for tissue engineering scaffolds: cells require high water content, as well as an adequate diffusion of nutrients, oxygen, and growth factors in order to grow and proliferate. High EWC percentages (94-95\%, Table 1) confirmed that the swellable click-

Table 1. Gelation Time (GT), Gelation Fraction (GF), and Swelling Kinetics (Equilibrium Water Content, EWC) of Hydrogels at $10 \mathrm{w} / \mathrm{v} \%$ in PBS Solution (1:1 Molar Ratio of Alkyne to Thiol End Groups) ${ }^{a}$

\begin{tabular}{|c|c|c|c|c|}
\hline & $\mathrm{GT}^{b}(\mathrm{~s})$ & GF (\%) & EWC (\%) & $\operatorname{Mesh~Size~}^{c}(\mathrm{~nm})$ \\
\hline $3_{1 \mathrm{~A}} 2_{1 \mathrm{~S}}$ & $210 \pm 7$ & $74 \pm 2.6$ & $95 \pm 0.9$ & $5.8 \pm 0.49$ \\
\hline $3_{1 \mathrm{~A}} 2_{2 \mathrm{~S}}$ & $290 \pm 10$ & $80 \pm 1.9$ & $94 \pm 0.8$ & $6.4 \pm 0.16$ \\
\hline $3_{1 \mathrm{~A}} 2_{3 \mathrm{~S}}$ & $438 \pm 5$ & $78 \pm 4.9$ & $95 \pm 0.1$ & $5.9 \pm 0.03$ \\
\hline $3_{1 \mathrm{~A}} 3_{1 \mathrm{~S}}$ & $26 \pm 3$ & $78 \pm 1.2$ & $90 \pm 0.2$ & $4.2 \pm 0.07$ \\
\hline $3_{1 A} 4_{2 S}$ & $25 \pm 9$ & $75 \pm 1.3$ & $90 \pm 0.5$ & $4.7 \pm 0.14$ \\
\hline $4_{2 \mathrm{~A}} 3_{1 S}$ & $15 \pm 5$ & $92 \pm 0.7$ & $87 \pm 1.7$ & $4.4 \pm 0.47$ \\
\hline $4_{2 A} 4_{2 s}$ & $11 \pm 2$ & $89 \pm 1.8$ & $86 \pm 0.9$ & $4.4 \pm 0.24$ \\
\hline $3_{1 \mathrm{~A}} 2 \mathrm{P}_{3 \mathrm{~S}}$ & $10 \mathrm{~min}$ & $79 \pm 1.3$ & $58 \pm 9.8$ & $1.2 \pm 0.48$ \\
\hline $3_{1 \mathrm{~A}} 2_{3 \mathrm{~S}-6040}$ & $8-10 \mathrm{~min}$ & $84 \pm 1.2$ & $86 \pm 0.2$ & $3.7 \pm 0.04$ \\
\hline
\end{tabular}

${ }^{a}$ The hydrogel naming $\left(\mathbf{X}_{\mathrm{ZA}} \mathbf{Y}_{\mathrm{ZS}}\right)$ denotes its structure, where $\mathbf{X}=$ number of arms of the alkyne precursor, $Y=$ number of arms of the thiol precursor, and $\mathbf{Z}=$ molecular weight of the PEG precursor. ${ }^{b}$ Measured via the vial tilt methods. ${ }^{c}$ Calculated from the FloryRehner equation (see SI).

hydrogels contained porous structures with the ability to hold large amounts of water. The average mesh size of these thiolyne networks, calculated using the Flory-Rehner equation, ${ }^{29}$ ranged between 5.8 and $6.4 \mathrm{~nm}$ (Table 1). Although the pore size of the hydrogels determined by Cryo-SEM observation differs from the previous values (i.e., pore size in the range of $\mu \mathrm{m})$, a porous structure was observed for the three systems (data not shown).

As expected, the swelling response of the control clickhydrogels $\left(3_{1 \mathrm{~A}} 2_{1 \mathrm{~S}}, 3_{1 \mathrm{~A}} 2_{2 \mathrm{~S}}\right.$, and $\left.3_{1 \mathrm{~A}} \mathbf{2}_{3 \mathrm{~S}}\right)$ had a significant negative effect on their mechanical performance (Figure 1). The compressive strength and modulus values decrease with immersion time (Figure $1 \mathrm{~b}$ and Table S2), which becomes more evident with increasing molecular weight of the thiolterminated PEG precursor. For instance, for the $\mathbf{3}_{1 \mathrm{~A}} \mathbf{2}_{3 \mathrm{~s}}$ system, the compressive modulus before and after $48 \mathrm{~h}$ of swelling was $33.6 \pm 2.6 \mathrm{kPa}$ and $5.6 \pm 1.1 \mathrm{kPa}$, respectively; whereas the compressive strength decreased from $2.4 \pm 0.3 \mathrm{MPa}$ to $1.0 \pm$ $0.05 \mathrm{MPa}$ during the same swelling time.

All the hydrogels broke when $98 \%$ strain was reached therefore demonstrating a hydrogel with longer, more flexible PEG chains can withstand large amounts of strain. However, these PEG chains also display a hydrophilic character, thus attracting more water molecules into the network, which in turn accelerates degradation rates and impairs the mechanical performance. Hence, to counteract this effect, we targeted specific modifications of the PEG precursors to render the click-hydrogels nonswellable (Scheme 2). The resulting nonswellable hydrogels were immersed in PBS solution at 37 ${ }^{\circ} \mathrm{C}$ for 30 days or until degradation, and their swelling response 
and mechanical properties in the swollen state were assessed periodically.

Characterization of Nonswellable PEG-Containing Click-Hydrogels. The water uptake of thiol-yne clickhydrogels immersed in PBS solution at $37{ }^{\circ} \mathrm{C}$ was effectively regulated by applying two straightforward approaches that are based on different principles. The first route relies on rendering the polymeric network more hydrophobic by increasing the number of cross-linking sites and also reducing the molecular weight of the hydrophilic polymer backbone.

Hence, in our multiarm thiol-yne hydrogel systems, the 2arm thiol-functionalized PEG precursor was replaced with either a 3- or 4-arm precursor (Scheme 2a). Four multiarm PEG precursors were synthesized $\left(3_{1 \mathrm{~S}}, \mathbf{3}_{1 \mathrm{~A}}, \mathbf{4}_{2 \mathrm{~S}}, \mathbf{4}_{2 \mathrm{~A}}\right)$, and accordingly four different click-hydrogel systems were prepared as a result of different combinations: $3_{1 \mathrm{~A}} 3_{1 S}, 3_{1 \mathrm{~A}} \mathbf{4}_{2 \mathrm{~S}}, \mathbf{4}_{2 \mathrm{~A}} 3_{1 \mathrm{~S}}$, and $4_{2 \mathrm{~A}} 4_{2 \mathrm{~S}}$.

In the second strategy, the polymeric network $3_{1 \mathrm{~A}} \mathbf{2} \mathbf{P}_{3 \mathrm{~S}}$ (Scheme 2b) was designed to contain thermoresponsive segments $\left(2 \mathbf{P}_{3 \mathrm{~S}}\right)$ that collapse above a certain temperature (i.e., cloud point $25-35^{\circ} \mathrm{C}$ ). Gel fraction (GF) values (Table 1 ), which indicate the efficiency of the cross-linking process, were higher than $74 \%$ for all the systems tested regardless of the followed route, thus highlighting the suitability of the nucleophilic thiol-yne chemistry for hydrogel synthesis.

Gelation Time. All the multiarm click-hydrogels formed almost immediately after mixing the alkyne- and thiolcontaining solutions. Gelation times for these systems, which were first determined by the vial tilt method, range between 11 and $26 \mathrm{~s}$ (Table 1). The high rate of reaction for the nucleophilic thiol-yne addition was attributed to the elevated number of cross-linking points that are now spatially closer, thus resulting in this rapid gelation. This effect is more pronounced for the $4_{2 A} 4_{2 S}$ hydrogel, which is formed with the 4-arm PEG precursors, which displays the highest number of reactive groups per molecule. In contrast, all the control systems, which are formed with a 2-arm thiol PEG precursors, displayed higher gelation times that increase with molecular weight.

The gelation time for the thermoresponsive hydrogel $\left(3_{1 \mathrm{~A}} \mathbf{2} \mathbf{P}_{3 \mathrm{~S}}\right)$ was slower $(10 \mathrm{~min})$ as a consequence of the low temperature during preparation, which affected the clickreaction rate. Lower temperatures were required as a consequence of the PEG precursors cloud point (cloud point $\left.25-35^{\circ} \mathrm{C}\right) .{ }^{17}$ The solution of the thiol-terminated Pluronic $\left(2 \mathbf{P}_{3 \mathrm{~S}}\right)$ at $10 \mathrm{wt} \%$ was cloudy at room temperature. Therefore, all the preparation steps for hydrogels containing $\mathbf{2} \mathbf{P}_{3 \mathrm{~S}}$ as the thiol moiety were performed below $10{ }^{\circ} \mathrm{C}$ by cooling the solutions in an ice bath. In doing so, we assured that the thermoresponsive polymer was completely soluble in the aqueous buffer for an effective cross-linking. After mixing the PEG-containing precursors, gelation proceeded at room temperature $\left(23^{\circ} \mathrm{C}\right)$, and the resulting hydrogels were completely transparent.

Among the different theories applied to the gelation of polymers, the Flory-Stockmayer theory states that gelation occurs when systems of high functionality produce an infinite molecular weight network through cross-linking provided that the reaction is carried far enough, thus shifting the system from the liquid to the gel phase. ${ }^{34-36}$ This definition is derived from the probability of finding a cross-linking point during gelation. Hence, the gelation point, which is defined at a certain extent of reaction, is reached when a critical number of intermolecular linkages have been exceeded. More specifically, this theory states that the theoretical critical amount of cross-links needed to form a gel, $p_{\mathcal{O}}$ can be calculated by using the following equation 6

$$
p_{\mathrm{c}}=\frac{1}{\sqrt{\frac{\left(f_{\mathrm{A}}-1\right)\left(f_{\mathrm{B}}-1\right)}{r}}}
$$

where $f_{\mathrm{A}}$ is the functionality of the alkyne PEG precursors, $f_{\mathrm{B}}$ is the functionality of the thiol PEG precursors, and $r$ is the ratio between the total number of alkyne and thiol groups (i.e., $r=1$ in our case because we are working under stoichiometric conditions). ${ }^{37}$

For our systems with a trifunctional alkyne precursor and a bifunctional thiol precursor (i.e., $3_{1 \mathrm{~A}} 2_{1 \mathrm{~S}}, 3_{1 \mathrm{~A}} 2_{2 \mathrm{~S}}, 3_{1 \mathrm{~A}} \mathbf{2}_{3 \mathrm{~S}}, 3_{1 \mathrm{~A}} 2 \mathrm{P}_{3 \mathrm{~S}}$, $\left.3_{1 \mathrm{~A}} 2_{3 \mathrm{~s}-6040}\right)$, the value that the Flory-Stockmayer theory predicts for $\alpha_{\mathrm{c}}$ is 0.71 , which means that gelation takes place when the amount of alkyne PEG precursors that have reacted is higher than $71 \%$. In the case of the multiarmed hydrogel systems with either a tri- or tetrafunctional PEG precursor, the value obtained for $\alpha_{c}$ is $0.50,0.41$, and 0.33 for $3_{1 \mathrm{~A}} 3_{1 \mathrm{~s}}, 3_{1 \mathrm{~A}} 4_{2 \mathrm{~s}}$ or $4_{2 \mathrm{~A}} 3_{1 \mathrm{~S}}$, and $4_{2 \mathrm{~A}} \mathbf{4}_{2 \mathrm{~S}}$, respectively, thus indicating that these systems reach the gelation point with fewer intermolecular linkages. Hence, although other factors such as temperature or molecular weight of the PEG precursors influence gelation, the gelation time values observed by the vial tilt method are in good agreement with the values predicted from the FloryStockmayer theory.

Swelling Profile. Both strategies were able to suppress swelling and thus control the increase in volume; however, the resulting click-hydrogels exhibited distinct swelling behaviors (Figure 2). In the multiarm click-hydrogels, the rate at which

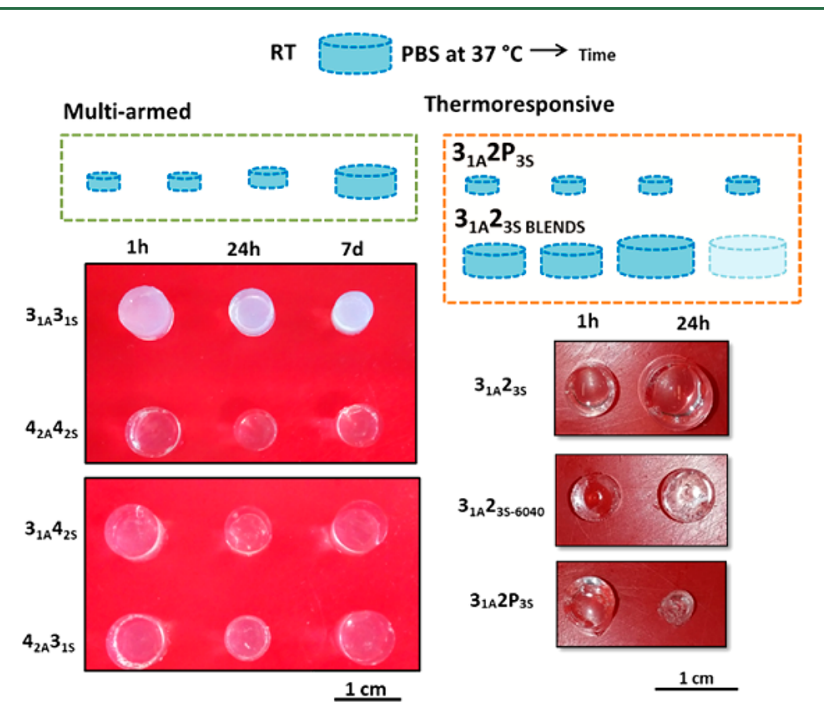

Figure 2. Thiol-yne click-hydrogels response when immersed in PBS solution at $37{ }^{\circ} \mathrm{C}$.

each hydrogel expelled and attracted water was dependent on the architecture of the thiol- and alkyne-terminated PEG precursors. All four systems rapidly shrunk after the initial $24 \mathrm{~h}$ immersed in PBS solution at $37^{\circ} \mathrm{C}$ (Figure 3a,b). We postulate that the increased density of cross-linked sites promotes the hydrophobic nature of the hydrogel network, thus repelling water out of system. Although the hydrogels remained unchanged for 5 days with swelling factor $(\mathrm{SF})$ values in the 


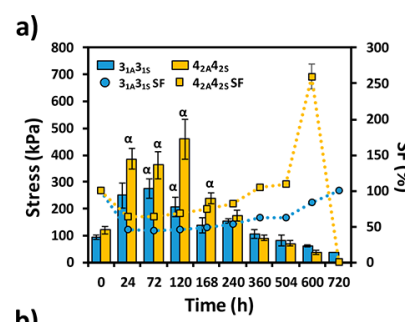

b)
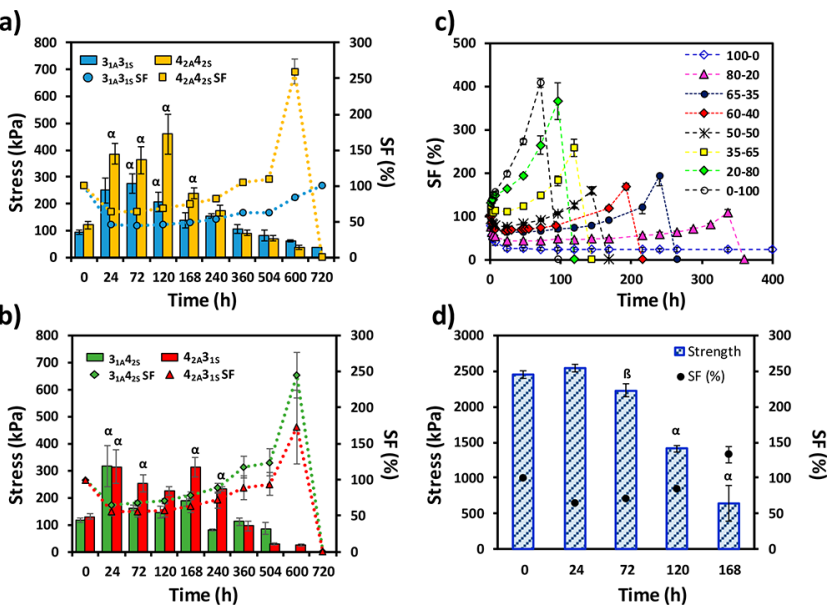

Figure 3. (a,b) Evolution of the compressive mechanical properties (bar data; left axis) with the SF (symbols, right axis) for the nonswellable nucleophilic thiol-yne PEG hydrogels displaying multiarm architecture: (a) $3{ }_{1 \mathrm{~A}} 3_{1 \mathrm{~S}}$ (blue circle) and $4_{2 \mathrm{~A}} 4_{2 \mathrm{~S}}$ (yellow square); (b) $3_{1 \mathrm{~A}} 4_{2 \mathrm{~S}}$ (green diamond) and $4_{2 \mathrm{~A}} 3_{1 \mathrm{~S}}$ (red triangle). Greek letters on the bars refer to significant differences ( $p$-value <0.05): $\alpha$ vs $1 \mathrm{~h}$. (c) SF (\%) as a function of time in PBS solution at $37{ }^{\circ} \mathrm{C}$ for $3_{1 \mathrm{~A}} 2_{3 \mathrm{~s}}$-blends; (d) compressive strength values with immersion time at $37{ }^{\circ} \mathrm{C}$ for $3_{1 \mathrm{~A}} \mathbf{2}_{3 \mathrm{~S}-6040}$ hydrogels. Greek letters on the bars refer to significant differences ( $p$-value $<0.05$ ): $\alpha$ vs all, $\beta$ vs 24,120 , and $168 \mathrm{~h}$.

range between $46 \% \pm 0.1 \%$ and $71 \% \pm 3.1 \%$, they started to swell back slowly to $100 \%$. After 21 days, signs of hydrogel degradation appeared which allowed an increased amount of water into the network, thus accelerating the swelling rate rapidly and in turn the degradation rate.

Moreover, despite the shrinkage of the polymeric network, multiarm PEG hydrogels also display high EWC values (between $86 \%$ and $90 \%$, Table 1) in comparison to control swellable hydrogels, which evidence that changes in the architecture of the PEG precursor have little effect on the network's ability to hold water. In contrast, they display a reduced average mesh size $(4.2-4.7 \mathrm{~nm})$ as a consequence of the increased number of cross-linking sites and shorter polymeric chains.

The $\mathbf{4}_{2 \mathrm{~A}} \mathbf{4}_{2 \mathrm{~S}}, \mathbf{4}_{2 \mathrm{~A}} \mathbf{3}_{1 \mathrm{~S}}$, and $\mathbf{3}_{1 \mathrm{~A}} \mathbf{4}_{2 \mathrm{~S}}$ behaved similarly; these systems shrunk to $64 \%$ after $24 \mathrm{~h}$ and then recovered, swelling up to $250 \%$ after 25 days in PBS solution before degrading completely. In contrast, the $3_{1 \mathrm{~A}} \mathbf{3}_{1 \mathrm{~S}}$ hydrogel displayed a SF of $45 \%$ after $24 \mathrm{~h}$, which is maintained for 7 days before the system starts to slowly swell to $100 \%$, with no signs of degradation after 30 days. Therefore, we propose that the ratio between cross-linked sites and the length of the PEG arm controls the swelling profile of multiarm click-hydrogels. Indeed, the $3_{1 \mathrm{~A}} 3_{1 \mathrm{~s}}$ system, which displays the shortest average arm length between each cross-linking site (i.e., $0.33 \mathrm{~kg} \mathrm{~mol}^{-1}$ ), results in a very dense system with enhanced hydrophobic nature and reduced ability to attract water. Consequently, the rate of ester hydrolysis is low in this system, which reduces the degradation rate of the polymeric network.

In contrast, the $\mathbf{3}_{1 \mathrm{~s}} \mathbf{2} \mathbf{P}_{3 \mathrm{~S}}$ click-hydrogels started to shrink almost immediately after immersing in PBS solution. The SF decreased to $27.1 \% \pm 5.4 \%$ after $21 \mathrm{~h}$, which indicates that water is quickly being expelled from the polymeric network (Figure S16a). However, at this point, the SF value remained constant for 30 days with a mean value of $24.5 \% \pm 1.5 \%$. Accordingly, the EWC value for $\mathbf{3}_{1 \mathrm{~A}} \mathbf{2} \mathbf{P}_{3 \mathrm{~S}}$ click-hydrogels is $58 \%$ $\pm 9.8 \%$. The low water content for this system is responsible for slowing down the hydrolysis of the ester bonds present in the polymeric network, and thus $\mathbf{3}_{1 \mathrm{~s}} \mathbf{2} \mathbf{P}_{3 \mathrm{~S}}$ hydrogels did not undergo any degradation process within the observed period of time, as opposed to multiarm click-hydrogels, which started to degrade after 21 days of swelling.

Nevertheless, $\mathbf{3}_{1 \mathrm{~A}} \mathbf{2} \mathbf{P}_{3 \mathrm{~S}}$ click-hydrogels can hardly be considered suitable materials for tissue scaffolds. Although their mechanical properties are adequate (vide infra), we suspected that their low water content might endanger the viability of cells encapsulated within. Hence, we decided to exert a more direct control over the swelling response of the system by blending $\mathbf{2} \mathbf{P}_{3 \mathrm{~S}}$ and $\mathbf{2}_{3 \mathrm{~s}}$ as thiol-terminated PEG precursors. Accordingly, hydrogels with varying $2 \mathrm{P}_{3 \mathrm{~s}}: \mathbf{2}_{3 \mathrm{~S}}$ molar ratio displayed an intermediate swelling response between that shown by $3_{1 \mathrm{~A}} \mathbf{2}_{3 \mathrm{~S}}$ and $\mathbf{3}_{1 \mathrm{~A}} \mathbf{2} \mathrm{P}_{3 \mathrm{~S}}$ (Figure 3c). Blended hydrogels with a content of $2 \mathrm{P}_{3 \mathrm{~S}}$ higher than $50 \%$ reached a stable $\mathrm{SF}$ below $100 \%$ within $20 \mathrm{~h}$, whereas hydrogels containing a higher proportion of the PEG precursor $\mathbf{2}_{35}$ underwent considerable swelling and degraded in less than 5 days. Thus, by varying the thermoresponsive content, not only does this approach allow for good control of the water uptake but also affects the degradation rate of the hydrogels, which are stable for a period of time that ranges between 5 and 15 days, and at least 30 days in the case of $100 \%$ Pluronic content (Figure S16a). Besides, all the thermoresponsive click-hydrogels retain their original transparency at $37{ }^{\circ} \mathrm{C}$ (Figure 2), which suggests that their network structure is homogeneous regardless the content of Pluronic content.

It is important to note a few considerations: the degree of swelling expected for an injectable hydrogel should be close to $100 \%$, which means just enough swelling for an "expansion fit" of the hydrogel within the void space. A considerable increase in volume could potentially damage the nearby tissue, causing pain and triggering an inflammatory response, while a sudden shrinkage not only implies low water content, but also results in a smaller hydrogel which will not fill the vacant space. Moreover, hydrogels as tissue engineering scaffolds are required to be mechanically stable and robust for as long as possible, allowing cells to adhere, grow, and eventually develop new tissue while the hydrogel slowly degrades.

Taking these considerations into account, we evaluated all the Pluronic thiol-yne hydrogels compositions and calculated (Figure S12a) that a click-hydrogel with a $\mathbf{2 P}_{3 \mathrm{~s}}: \mathbf{2}_{3 \mathrm{~S}}$ molar ratio of $60: 40$ (hereafter denoted $3_{1 \mathrm{~A}} \boldsymbol{2}_{3 \mathrm{~s}-6040}$ ) met the required criteria for further characterization. Indeed, this system, which displays a gelation time of $8-10 \mathrm{~min}$ and a GF value of $84 \% \pm$ $0.2 \%$ (Table 1), exhibits a mean SF of $71.0 \% \pm 4.4 \%$ for an overall period of 7 days, when it finally starts to swell and degrades (day 10) (Figure 3c). The polymeric network of the blended click-hydrogel $3_{1 \mathrm{~A}} 2_{3 \mathrm{~S}-6040}$ does not shrink as abruptly as in the case of $3_{1 \mathrm{~A}} 2 \mathrm{P}_{3 \mathrm{~S}}$, thus the hydrogel still retains a high amount of water at $37{ }^{\circ} \mathrm{C}$ (EWC is $\left.86.0 \pm 0.2 \%\right)$. However, despite the presence of thermoresponsive units, the immersion temperature has a severe effect on the hydrogel's degradation rate (Figure S12b); $\mathbf{3}_{1 \mathrm{~A}} \mathbf{2}_{3 \mathrm{~S}-6040}$ hydrogels immersed in PBS solution at RT and $4{ }^{\circ} \mathrm{C}$ display longer stability (22 and at least 37 days, respectively).

Morphology. As a consequence of the general collapse of the thermoresponsive click-hydrogel network, the mesh pore size derived from swelling kinetics was calculated to be $1.2 \pm 0.48$ $\mathrm{nm}$ and $3.7 \pm 0.04 \mathrm{~nm}$ for $\mathbf{3}_{1 \mathrm{~A}} \mathbf{2} \mathrm{P}_{3 \mathrm{~S}}$ and $\mathbf{3}_{1 \mathrm{~A}} \mathbf{2}_{3 \mathrm{~S}-6040}$ hydrogels, respectively. Both values are clearly smaller than those 
displayed by multiarm PEG hydrogels $(4.2-4.7 \mathrm{~nm})$ showing a dependence on the mesh size with swelling. These mesh sizes could affect how cells interact with the network as it has been reported that smaller mesh size and stiffer matrices restrict 3D cell spreading, ${ }^{38}$ as well as influence cell morphology. ${ }^{39-41}$

Cryo-SEM characterization was also conducted to understand the morphology of the networks and the correlation between ice crystal growth and the different PEG precursors. For all systems, the structure revealed is porous (Figure 4 and
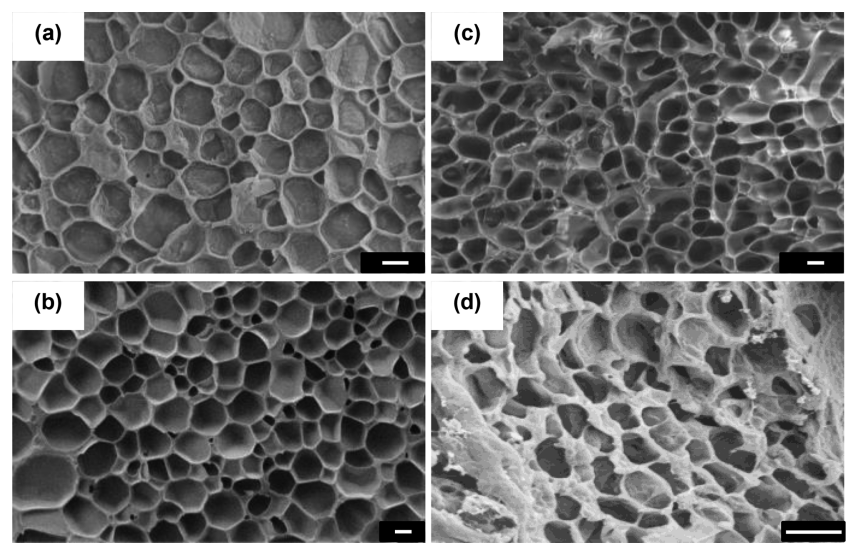

Figure 4. Cryo-SEM images of nonswellable thiol-yne PEG hydrogels: (a) $3_{1 \mathrm{~A}} 2_{3 \mathrm{~S}}$, (b) $3_{1 \mathrm{~A}} 3_{1 \mathrm{~S}}$, (c) $3_{1 \mathrm{~A}} 2 \mathrm{P}_{3 \mathrm{~S}}$, and (d) $3_{1 \mathrm{~A}} 2_{3 \mathrm{~S}-6040}$ $($ Scale bar $=2 \mu \mathrm{m})$.

S13) with a range of different sizes that ice crystals can grow to during the freezing process. The difference sizes ranged between $1.64 \pm 0.36 \mu \mathrm{m}$ and $4.20 \pm 2.74 \mu \mathrm{m}$, which corresponded to $3_{1 \mathrm{~A}} \mathbf{2}_{3 \mathrm{~S}-6040}$ and $\mathbf{4}_{2 \mathrm{~A}} \mathbf{4}_{2 \mathrm{~S}}$, respectively (Figure S14). Multiarm click-hydrogels prepared with $\mathbf{4}_{2 \mathrm{~A}}$ exhibited a much broader distribution of ice crystal sizes, while using $3_{1 \mathrm{~A}}$ resulted in click hydrogels with a more homogeneous structure. Additionally, the ice crystal structure for the $3_{1 \mathrm{~A}} \mathbf{4}_{2 \mathrm{~S}}$ is significantly smaller in comparison to the other three multiarm hydrogel systems. Similarly, thermoresponsive hydrogels, which are prepared with $3_{1 \mathrm{~A}}$, also reveal a narrower and more homogeneous distribution of ice crystals. Consequently, using $\mathbf{3}_{1 \mathrm{~A}}$ as alkyne-modified PEG precursor results in hydrogel networks which are more densely packed, which could influence cell behavior.

Rheological Characterization. Rheological tests were carried out to fully evaluate the viscoelastic properties of the nonswellable thiol-yne click-hydrogels and determine any possible drawback derived from either of the approaches followed to suppress the swelling response. For comparison purposes, the control hydrogel $3_{1 \mathrm{~A}} \mathbf{2}_{3 \mathrm{~S}}$ was also characterized.

First, by monitoring the evolution of both the storage $\left(G^{\prime}\right)$ and loss $\left(G^{\prime \prime}\right)$ moduli of a sample with time, the gelation time, which is defined as the crossover point between $G^{\prime}$ and $G^{\prime \prime}$, can be determined. The gelation time for the four multiarm systems was within $30 \mathrm{~s}$ (Figure 5a), which is in good agreement with the results from the vial tilt method, thus indicating that the hydrogels are fully cross-linked into stable and robust networks despite the quick gelation process. As previously observed, increasing the concentration of reactive end groups in solution reduces the gelation time. The click hydrogels with thermoresponsive units showed a gelation time of about 10 min (Figure 5c) and also present a stable structure after $25 \mathrm{~min}$.
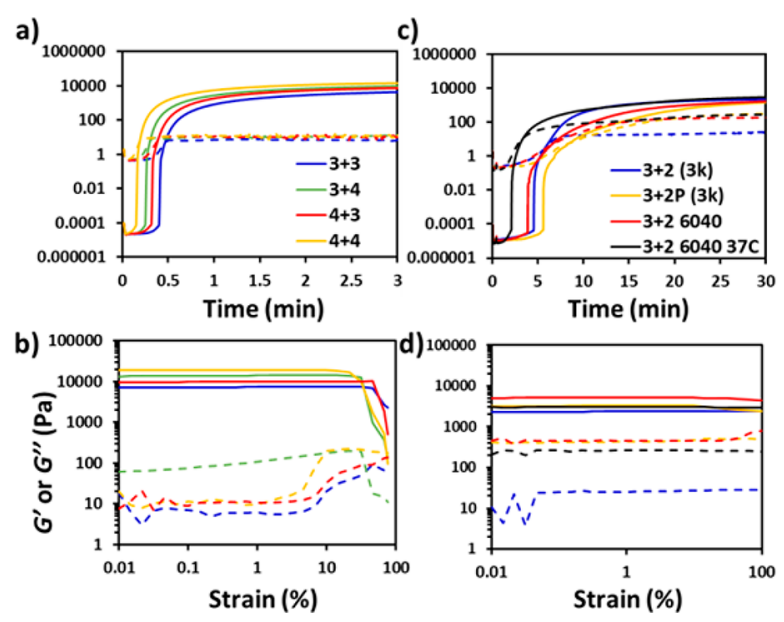

Figure 5. Representative curves of storage $\left(G^{\prime}\right.$; solid line) and loss ( $G^{\prime \prime}$; dashed line) modulus as a function of $(a, c)$ time, and $(b, d)$ strain for nonswellable PEG click-hydrogels with multiarm architecture (left column) and thermoresponsive units (right column).

The viscoelastic properties were determined by monitoring the storage $\left(G^{\prime}\right)$ and loss $\left(G^{\prime \prime}\right)$ moduli as the strain on the hydrogel increased (Figure $5 \mathrm{~b}$ ). All the multiarm hydrogels showed high $G^{\prime}$, which is indicative of highly viscoelastic materials. Moreover, $G^{\prime}$ increased with the number of functional groups per molecule, thus suggesting that a more rigid structure is formed as a consequence of the higher density of cross-linking points. Consequently, the stiffer materials were unable to withstand high levels of strain. For instance, $G^{\prime}$ decreases at $32 \%$ of strain for $4_{2 A} 4_{2 A}$ and $3_{1 A} 4_{2 S}$, whereas clickhydrogels with a more elastic network $\left(4_{2 \mathrm{~A}} 3_{1 \mathrm{~S}}\right.$ and $\left.3_{1 \mathrm{~A}} 3_{1 \mathrm{~S}}\right)$ start to yield at higher strain (47\%). In contrast, the thermoresponsive click-hydrogels exhibited $G^{\prime}$ values which are similar to the control hydrogel $3_{1 \mathrm{~A}} \mathbf{2}_{3 \mathrm{~S}}$ and comparable to those displayed by multiarm click-hydrogels (Figure $5 \mathrm{~d}$ and Table S3) regardless of their composition.

Moreover, the high $G^{\prime}$ values remained stable during the whole amplitude sweep range, even at high strain, which reveals a more elastic nature of the polymeric network as a consequence of using 2-arm instead of 3- or 4-arm thiolfunctionalized PEG precursors. Therefore, although the architecture of the PEG precursors affects the viscoelastic properties of the resulting click-hydrogels, it can be exploited to finely tune these features, which can be potentially useful for biological applications, such as tuning the scaffold stiffness to influence cell morphology and spreading. ${ }^{38-40}$

Furthermore, temperature had no significant effect on the rheological properties of the blended click-hydrogel $3_{1 \mathrm{~A}} \mathbf{2}_{3 \mathrm{~S}-6040}$; both $G^{\prime}$ and $G^{\prime \prime}$ were retained despite the partial shrinkage of the hydrogel at $37^{\circ} \mathrm{C}$, thus further confirming the suitability of this system for an in vivo bioapplication.

Mechanical Characterization in the Swollen State. Uniaxial compression testing was performed over a 30-day swelling period to evaluate the mechanical performance of nonswellable PEG-containing click-hydrogels in the swollen state. Specifically, hydrogels were prepared and left to cure for 1 $\mathrm{h}$ to allow for the hydrogels to be fully cross-linked, before immersing them in PBS solution at $37^{\circ} \mathrm{C}$. After a set period of time, their mechanical properties were characterized.

The thiol-yne multiarm click-hydrogels presented a range of compressive strengths that was related to both their swelling factor (SF) and immersion time. After the initial $24 \mathrm{~h}$ in PBS 
solution at $37{ }^{\circ} \mathrm{C}$, their compressive strength values increased (Figure S15). Specifically, for the $\mathbf{4}_{2 \mathrm{~A}} \mathbf{4}_{2 \mathrm{~S}}$ system, which displayed the greatest change, the compressive strength increased from $120 \pm 13 \mathrm{kPa}$ to $385 \pm 37.5 \mathrm{kPa}$ in $24 \mathrm{~h}$ (Figure 3a,b, Tables S2 and S3). This response is in good agreement with the decrease of the SF. As water molecules are expelled from the hydrogel network, the polymer content increases and the mechanical properties of the multiarm hydrogels improve. Moreover, as long as the SF remained constant, no changes in the mechanical performance were observed. For instance, the $\mathbf{3}_{1 \mathrm{~A}} \mathbf{4}_{2 \mathrm{~S}}$ system reached its maximum strength after $24 \mathrm{~h}$, while the $\mathbf{4}_{2 \mathrm{~A}} \mathbf{4}_{2 \mathrm{~S}}$ system displayed its highest stress values after 5 days, which also reflects the unique properties of each one of the click-hydrogels based on the molecular weight of the PEG precursors, as well as their swelling response.

However, when the swelling factor increased past $100 \%$ (after 15 days), the mechanical properties of the multiarm clickhydrogels were severely compromised. Once swollen, the accelerated rate of ester hydrolysis promotes the degradation process and thus weakens the hydrogel structure, which is reflected by a reduction in the compressive strength after 25 days of immersion. Finally, when SF values higher than $150 \%$ were reached, the click-hydrogels degraded very rapidly and dissolved into the PBS solution.

It is important to note that the compressive strength values exhibited by multiarm click-hydrogels are not as high as those displayed by the control swellable systems, mainly as a consequence of the increased stiffness of the system. The polymeric chains are highly cross-linked and unable to adapt and withstand an external stress; the multiarm hydrogels break at lower strain values $(48-66 \%$ for the multiarm series versus 95-96\% for the thermoresponsive series Table S2). Nevertheless, despite this fact, they are able to retain their mechanical performance over time in the swollen state for longer (Figures $3 \mathrm{a}, \mathrm{b}$ and S17), and thus can be effectively applied as biodegradable scaffolds for soft tissue regeneration in a biological context where extremely robust hydrogels are not required.

Similar to the response displayed by the multiarm nonswellable hydrogels, the mechanical performance of $3_{1 \mathrm{~A}} 2 \mathbf{P}_{3 \mathrm{~s}}$ clickhydrogels was altered after being immersed in PBS solution at $37{ }^{\circ} \mathrm{C}$ (Figure S16, Tables S2 and S3). However, in contrast to the multiarm system, the high compressive strengths observed in the related hydrogels that we have previously reported ${ }^{16}$ were maintained. Specifically, after only $24 \mathrm{~h}$ of immersion time, both the compressive strength and Young's Modulus of the system increased from $2.5 \pm 0.2 \mathrm{MPa}$ and $18 \pm 2.2 \mathrm{kPa}$ (i.e., values comparable to those displayed by control swellable hydrogels) to $5.5 \pm 0.2 \mathrm{MPa}$ and $83.7 \pm 11.3 \mathrm{kPa}$, respectively, a fact that is attributed also to the low water content in the hydrogel, which makes it extremely strong; hydrogels were rubbery and did not break after reaching $98 \%$ compression during testing. Since the SF of $\mathbf{3}_{1 \mathrm{~A}} \mathbf{2} \mathbf{P}_{3 \mathrm{~S}}$ click-hydrogels does not change significantly with time after a constant SF value of about $25 \%$ is reached after $24 \mathrm{~h}$ (i.e., no degradation process was observed as opposed to multiarm click-hydrogels), they retain this excellent mechanical performance even after 14 days of immersion (Figure S16).

Finally, we confirmed that, as long as the blended clickhydrogel $3_{1 \mathrm{~A}} \mathbf{2}_{3 \mathrm{~s}-6040}$ is not highly swollen, the mechanical performance is preserved (Figure $3 \mathrm{~d}$ and S17). The high compressive strength of the blended system, which is $2.5 \pm$
$0.06 \mathrm{MPa}$ as-prepared, is significantly lower after 5 and 7 days of swelling $(1.4 \pm 0.04 \mathrm{MPa}$ and $0.64 \pm 0.25 \mathrm{MPa}$, respectively). Although there is indeed a decrease in the mechanical performance, the compressive strength values shown by the swollen blended click-hydrogels $3_{1 \mathrm{~A}} \mathbf{2}_{35-6040}$ are still high. Furthermore, the Young's modulus experiences a similar decreasing trend, from $23.7 \pm 1.9 \mathrm{kPa}$ to $8.1 \pm 1.7 \mathrm{kPa}$ and $5.8 \pm 2.2 \mathrm{kPa}$ after 5 and 7 days of swelling, respectively.

Overall, the major factor influencing the thiol-yne click hydrogels mechanical response is the swelling degree, and thus the condition of the polymeric matrix. ${ }^{25}$ On the one hand, the architecture of the PEG precursors has a fundamental influence on the swelling response of the resultant multiarm thiol-yne click-hydrogels, which in turn affects their compressive strength. Although the multiarm click-hydrogels display lower compressive strength values in comparison to the thermoresponsive systems (but within the range of soft load bearing tissue), their enhanced stability allowed them to retain their mechanical performance for at least 15 days. On the other hand, fine tuning of the swelling response as well as the degradation rate of robust thermoresponsive thiol-yne clickhydrogels is obtained by controlling the molar ratio of thiolterminated PEG precursors $\left(\mathbf{2 P}_{3 \mathrm{~S}}\right.$ and $\left.\mathbf{2}_{3 \mathrm{~S}}\right)$.

Assessing the Biocompatibility of Nonswellable ClickHydrogels. Finally, to evaluate the suitability of thiol-yne nonswellable click-hydrogels in a biological setting, their biocompatibility was assessed. A representative hydrogel of each route was chosen, $\mathbf{3}_{1 \mathrm{~A}} \mathbf{4}_{2 \mathrm{~S}}$ as multiarm click-hydrogel and $\mathbf{3}_{1 \mathrm{~A}} \mathbf{2}_{3 \mathrm{~S}-6040}$ as the thermoresponsive hydrogel. Also, $\mathbf{3}_{1 \mathrm{~A}} \mathbf{2 \mathbf { P } _ { 3 \mathrm { S } }}$ (100\% Pluronic content) and $3_{1 \mathrm{~A}} \mathbf{2}_{3 \mathrm{~S}}$ (2-arm thiol-terminated PEG-3k) hydrogels were used as control systems.

First, cell viability tests on MC3T3-E1 (murine preosteoblasts) cells were conducted by seeding them on top of the hydrogels, which had been prepared in situ directly in the wells of the TCPS plates, thus no washing steps were applied to the hydrogels. After $72 \mathrm{~h}$ the cell's metabolic activity was measured using PrestoBlue metabolic assay (Figure S18). All hydrogels demonstrated high cell viability which indicated that the clickhydrogel networks are biocompatible once formed. Most importantly, the extended time points reveal that within that incubation time, their degradation products are not cytotoxic, which further reinforces their potential as tissue engineering scaffolds able to support cell growth.

Following the promising initial results, 3D cell encapsulation experiments were also undertaken, and cell viability was assessed after 24 and $72 \mathrm{~h}$ of incubation by live-dead fluorescent staining (Figure 6). Since the preparation of the
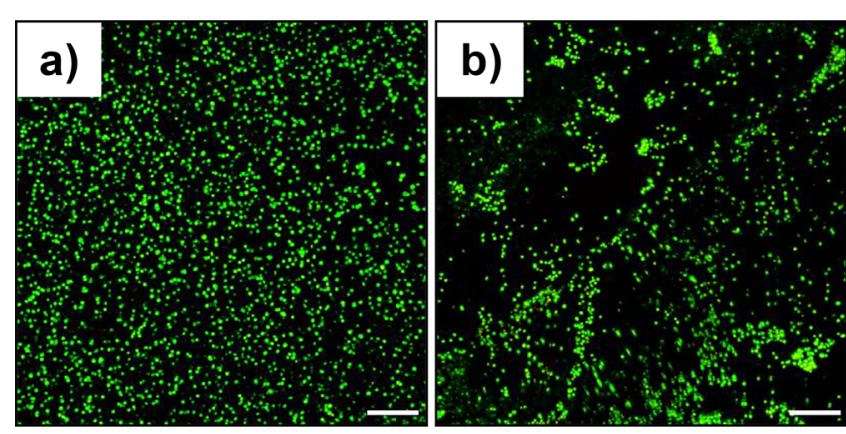

Figure 6. Biocompatibility of nonswellable thiol-yne PEG clickhydrogels. Images from 3D encapsulated cells after $72 \mathrm{~h}$ of incubation for (a) $3_{1 A} 4_{2 S}$ and (b) $3_{1 A} 2_{3 s-6040}$. Scale bar is $200 \mu \mathrm{m}$. 
thermoresponsive hydrogels is performed at low temperature, another control system that consisted in preparing $\mathbf{3}_{1 \mathrm{~A}} \mathbf{2}_{3 \mathrm{~s}}$ at low temperature was also included. After $24 \mathrm{~h}$ of incubation, all the hydrogels showed high cell viability with $>95 \%$ live cells, which indicates that the materials are nontoxic at this stage (Figure S19). Moreover, we confirmed that the low preparation temperature had no effect on cell viability. In contrast, after a longer incubation time $(72 \mathrm{~h})$, a high percentage of cell death was observed only for the thermoresponsive hydrogel $3_{1 \mathrm{~A}} \mathbf{2} \mathbf{P}_{3 \mathrm{~S}}$, which contains $100 \%$ of Pluronic as thiol-terminated precursor (Figure S18). Both the blended PEG/Pluronic click-hydrogels and the multiarm PEG hydrogels displayed high percentage of live cells, and hence we attribute the low cell viability of encapsulated cells within $\mathbf{3}_{1 \mathrm{~A}} \mathbf{2} \mathbf{P}_{3 \mathrm{~S}}$ hydrogel to several factors: the severe collapse of the polymeric network $(\mathrm{SF}=24.5 \% \pm$ $1.5 \%)$, the small mesh size $(1.2 \pm 0.48 \mathrm{~nm})$, the low water content of the hydrogel $(58 \% \pm 9.8 \%)$, as well as the cytotoxic effect of $\mathbf{2 P}_{3 S}$ (Figure S21). Interestingly, the stiffer nature of the multiarm $3_{1 \mathrm{~A}} 4_{2 \mathrm{~S}}$ click-hydrogel did not affect the viability of $3 \mathrm{D}$ encapsulated cells.

\section{CONCLUSIONS}

The design of a biomaterial device that perfectly matches all the requirements for a specific biological context is challenging. Here, we have presented two approaches to overcome the negative effect of water uptake on the mechanical properties of robust click-hydrogels cross-linked by thiol-yne nucleophilic addition. Through the judicious choice of the alkyne- and thiolterminated poly(ethylene glycol)-based precursors, either multiarm or thermoresponsive, the nonswellable click-hydrogels preserve their mechanical performance in the swollen state over time, as well as displaying good viscoelastic properties and finely tunable degradation rates. Most importantly, both approaches yielded nonswellable click-hydrogels that are highly biocompatible. Not only were cells able to adhere and grow on the top surface of the hydrogels, but they were also viable when encapsulated within the polymeric network as long as the water content and mesh size allow for adequate diffusion of oxygen and nutrients. Therefore, this work highlights the suitability of nonswellable click-hydrogels prepared by efficient thiol-yne chemistry as potential candidates to address the major issues of hydrogels as biomaterials.

\section{ASSOCIATED CONTENT}

\section{S Supporting Information}

The Supporting Information is available free of charge on the ACS Publications website at DOI: 10.1021/acs.biomac.7b01204.

NMR and SEC data of alkyne and thiol precursors, LCST data for Pluonic $3 \mathrm{k}(\mathrm{SH})_{2}\left(\mathbf{2 P}_{3 \mathrm{~S}}\right)$, additional hydrogel characterization data (PDF)

\section{AUTHOR INFORMATION}

\section{Corresponding Author}

*E-mail: a.p.dove@warwick.ac.uk.

ORCID 1

Andrew P. Dove: 0000-0001-8208-9309

\section{Author Contributions}

The manuscript was written through contributions of all authors. All authors have given approval to the final version of the manuscript.

\section{Author Contributions}

${ }^{\ddagger}$ L.J.M. and M.M.P.-.M. contributed equally.

\section{Notes}

The authors declare no competing financial interest.

\section{ACKNOWLEDGMENTS}

Prof. Matthew Gibson is thanked for giving access to his cell lab facilities. The University of Warwick Advanced BioImaging Research Technology Platform, BBSRC ALERT14 award BB/ $\mathrm{M} 01228 X / 1$ are thanked for confocal fluorescence microscopy analysis. M.M.P.-M. acknowledges funding from the European Union's Horizon 2020 research and innovation programme under the Marie Sklodowska-Curie grant agreement No 703415. EPSRC are thanked for the award of a DTP studentship to L. J. M. and ERC are acknowledged for support to M. C. A and A. P. D. (grant number: 681559)

\section{ABBREVIATIONS}

PEG, poly(ethylene glycol); PBS, phosphate buffer saline

\section{REFERENCES}

(1) Kamata, H.; Li, X.; Chung, U.-i.; Sakai, T. Design of Hydrogels for Biomedical Applications. Adv. Healthcare Mater. 2015, 4 (16), 2360-2374.

(2) Gyles, D. A.; Castro, L. D.; Silva, J. O. C.; Ribeiro-Costa, R. M. A review of the designs and prominent biomedical advances of natural and synthetic hydrogel formulations. Eur. Polym. J. 2017, 88, 373-392.

(3) Tam, R. Y.; Smith, L. J.; Shoichet, M. S. Engineering Cellular Microenvironments with Photo- and Enzymatically Responsive Hydrogels: Toward Biomimetic 3D Cell Culture Models. Acc. Chem. Res. 2017, 50 (4), 703-713.

(4) Li, Y.; Rodrigues, J.; Tomas, H. Injectable and biodegradable hydrogels: gelation, biodegradation and biomedical applications. Chem. Soc. Rev. 2012, 41 (6), 2193-2221.

(5) Slaughter, B. V.; Khurshid, S. S.; Fisher, O. Z.; Khademhosseini, A.; Peppas, N. A. Hydrogels in Regenerative Medicine. Adv. Mater. 2009, 21 (32-33), 3307-3329.

(6) Huang, Q.; Zou, Y.; Arno, M. C.; Chen, S.; Wang, T.; Gao, J.; Dove, A. P.; Du, J. Hydrogel scaffolds for differentiation of adiposederived stem cells. Chem. Soc. Rev. 2017, 46, 6255.

(7) Kharkar, P. M.; Kiick, K. L.; Kloxin, A. M. Designing degradable hydrogels for orthogonal control of cell microenvironments. Chem. Soc. Rev. 2013, 42 (17), 7335-7372.

(8) Azagarsamy, M. A.; Anseth, K. S. Bioorthogonal Click Chemistry: An Indispensable Tool to Create Multifaceted Cell Culture Scaffolds. ACS Macro Lett. 2013, 2 (1), 5-9.

(9) Ko, D. Y.; Shinde, U. P.; Yeon, B.; Jeong, B. Recent progress of in situ formed gels for biomedical applications. Prog. Polym. Sci. 2013, 38 (3), 672-701.

(10) Xu, L.; Sheybani, N.; Yeudall, W. A.; Yang, H. The effect of photoinitiators on intracellular AKT signaling pathway in tissue engineering application. Biomater. Sci. 2015, 3 (2), 250-255.

(11) Williams, C. G.; Malik, A. N.; Kim, T. K.; Manson, P. N.; Elisseeff, J. H. Variable cytocompatibility of six cell lines with photoinitiators used for polymerizing hydrogels and cell encapsulation. Biomaterials 2005, 26 (11), 1211-1218.

(12) Macaya, D.; Spector, M. Injectable hydrogel materials for spinal cord regeneration: a review. Biomed. Mater. 2012, 7 (1), 012001.

(13) Truong, V. X.; Dove, A. P. Organocatalytic, Regioselective Nucleophilic "Click" Addition of Thiols to Propiolic Acid Esters for Polymer-Polymer Coupling. Angew. Chem., Int. Ed. 2013, 52 (15), 4132-4136.

(14) Truong, V. X.; Ablett, M. P.; Richardson, S. M.; Hoyland, J. A.; Dove, A. P. Simultaneous Orthogonal Dual-Click Approach to Tough, in-Situ-Forming Hydrogels for Cell Encapsulation. J. Am. Chem. Soc. 2015, 137 (4), 1618-1622. 
(15) Cai, X. Y.; Li, J. Z.; Li, N. N.; Chen, J. C.; Kang, E.-T.; Xu, L. Q. PEG-based hydrogels prepared by catalyst-free thiol-yne addition and their post-antibacterial modification. Biomater. Sci. 2016, 4 (11), $1663-1672$.

(16) Macdougall, L. J.; Truong, V. X.; Dove, A. P. Efficient In Situ Nucleophilic Thiol-yne Click Chemistry for the Synthesis of Strong Hydrogel Materials with Tunable Properties. ACS Macro Lett. 2017, 6 (2), 93-97.

(17) Truong, V. X.; Tsang, K. M.; Forsythe, J. S. Nonswelling ClickCross-Linked Gelatin and PEG Hydrogels with Tunable Properties Using Pluronic Linkers. Biomacromolecules 2017, 18 (3), 757-766.

(18) Chung, C.; Lampe, K. J.; Heilshorn, S. C. Tetrakis(hydroxymethyl) Phosphonium Chloride as a Covalent Cross-Linking Agent for Cell Encapsulation within Protein-Based Hydrogels. Biomacromolecules 2012, 13 (12), 3912-3916.

(19) Dai, X.; Zhang, Y.; Gao, L.; Bai, T.; Wang, W.; Cui, Y.; Liu, W. A Mechanically Strong, Highly Stable, Thermoplastic, and Self-Healable Supramolecular Polymer Hydrogel. Adv. Mater. 2015, 27 (23), 35663571 .

(20) Luo, F.; Sun, T. L.; Nakajima, T.; Kurokawa, T.; Zhao, Y.; Sato, K.; Ihsan, A. B.; Li, X.; Guo, H.; Gong, J. P. Oppositely Charged Polyelectrolytes Form Tough, Self-Healing, and Rebuildable Hydrogels. Adv. Mater. 2015, 27 (17), 2722-2727.

(21) Itagaki, H.; Kurokawa, T.; Furukawa, H.; Nakajima, T.; Katsumoto, Y.; Gong, J. P. Water-Induced Brittle-Ductile Transition of Double Network Hydrogels. Macromolecules 2010, 43 (22), 94959500

(22) Wang, T.; Liu, D.; Lian, C.; Zheng, S.; Liu, X.; Tong, Z. Large deformation behavior and effective network chain density of swollen poly(N-isopropylacrylamide)-Laponite nanocomposite hydrogels. Soft Matter 2012, 8 (3), 774-783.

(23) Chen, H.; Yang, F.; Hu, R.; Zhang, M.; Ren, B.; Gong, X.; Ma, J.; Jiang, B.; Chen, Q.; Zheng, J. A comparative study of the mechanical properties of hybrid double-network hydrogels in swollen and asprepared states. J. Mater. Chem. B 2016, 4 (35), 5814-5824.

(24) Kamata, H.; Kushiro, K.; Takai, M.; Chung, U.-i.; Sakai, T. NonOsmotic Hydrogels: A Rational Strategy for Safely Degradable Hydrogels. Angew. Chem. 2016, 128 (32), 9428-9432.

(25) Kamata, H.; Akagi, Y.; Kayasuga-Kariya, Y.; Chung, U.-i.; Sakai, T. Nonswellable" Hydrogel Without Mechanical Hysteresis. Science 2014, 343 (6173), 873-875.

(26) Klouda, L. Thermoresponsive hydrogels in biomedical applications. Eur. J. Pharm. Biopharm. 2015, 97, 338-349.

(27) Koetting, M. C.; Peters, J. T.; Steichen, S. D.; Peppas, N. A. Stimulus-responsive hydrogels: Theory, modern advances, and applications. Mater. Sci. Eng., R 2015, 93, 1-49.

(28) Zustiak, S. P.; Leach, J. B. Hydrolytically Degradable Poly(Ethylene Glycol) Hydrogel Scaffolds with Tunable Degradation and Mechanical Properties. Biomacromolecules 2010, 11 (5), 13481357.

(29) Canal, T.; Peppas, N. A. Correlation between mesh size and equilibrium degree of swelling of polymeric networks. J. Biomed. Mater. Res. 1989, 23 (10), 1183-1193.

(30) Uhrich, K. E.; Cannizzaro, S. M.; Langer, R. S.; Shakesheff, K. M. Polymeric Systems for Controlled Drug Release. Chem. Rev. 1999, 99 (11), 3181-3198.

(31) Brannigan, R. P.; Dove, A. P. Synthesis, properties and biomedical applications of hydrolytically degradable materials based on aliphatic polyesters and polycarbonates. Biomater. Sci. 2017, 5 (1), 921.

(32) Nair, L. S.; Laurencin, C. T. Biodegradable polymers as biomaterials. Prog. Polym. Sci. 2007, 32 (8), 762-798.

(33) Lyu, S.; Untereker, D. Degradability of Polymers for Implantable Biomedical Devices. Int. J. Mol. Sci. 2009, 10 (9), 4033.

(34) Flory, P. J. Molecular Size Distribution in Three Dimensional Polymers. I. Gelation1. J. Am. Chem. Soc. 1941, 63 (11), 3083-3090.

(35) Flory, P. J. Constitution of Three-dimensional Polymers and the Theory of Gelation. J. Phys. Chem. 1942, 46 (1), 132-140.
(36) Stockmayer, W. H. Theory of molecular size distribution and gel formation in branched-chain polymers. J. Chem. Phys. 1943, 11 (2), $45-55$.

(37) Schultz, K. M.; Anseth, K. S. Monitoring degradation of matrix metalloproteinases-cleavable PEG hydrogels via multiple particle tracking microrheology. Soft Matter 2013, 9 (5), 1570-1579.

(38) Sala, A.; Hanseler, P.; Ranga, A.; Lutolf, M. P.; Voros, J.; Ehrbar, M.; Weber, F. E. Engineering 3D cell instructive microenvironments by rational assembly of artificial extracellular matrices and cell patterning. Integr. Biol. 2011, 3 (11), 1102-1111.

(39) Engler, A. J.; Sen, S.; Sweeney, H. L.; Discher, D. E. Matrix Elasticity Directs Stem Cell Lineage Specification. Cell 2006, 126 (4), 677-689.

(40) Kyburz, K. A.; Anseth, K. S. Three-dimensional hMSC motility within peptide-functionalized PEG-based hydrogels of varying adhesivity and crosslinking density. Acta Biomater. 2013, 9 (5), 6381-6392.

(41) Discher, D. E.; Janmey, P.; Wang, Y.-1. Tissue Cells Feel and Respond to the Stiffness of Their Substrate. Science 2005, 310 (5751), $1139-1143$ 